\title{
Recent advancement in 3-D printing: nanocomposites with added functionality
}

\author{
Wu Hui-Yan Clarissa ${ }^{1} \cdot$ Chin Hua Chia $^{2}$ (D) Sarani Zakaria ${ }^{2}$ (D) Yang Chia-Yan Evyan ${ }^{1}$ (])
}

Received: 21 May 2021 / Accepted: 17 October 2021 / Published online: 30 October 2021

(c) The Author(s), under exclusive licence to Springer Nature Switzerland AG 2021

\begin{abstract}
Three-Dimentional (3-D) printing is currently a popular printing technique that is used in many sectors. Potentially, this technology is expected to replace conventional manufacturing in the coming years. It is accelerating in gaining attention due to its design freedom where objects can be produced without imagination boundaries. The review presents a perspective on the application of 3-D printing application based on various fields. However, the ordinary 3-D printed products with a single type of raw often lack robustness leading to broken parts. Improving the mechanical property of a 3-D printed part is crucial for its applications in many fields. One of the promising solutions is to incorporate nanoparticles or fillers into the raw material. The review aims to provide information about the types of additive manufacturing. There are few types of raw materials can be used as foundation template in the printing, enhanced properties of the printed polymer nanocomposites with different types of nanoparticles as additives in the printing. The article reviews the advantages and disadvantages of different materials that are used as raw materials or base materials in 3-D printing. This can be a guideline for the readers to compare and analyse the raw materials prior to a decision on the type of material to be selected. The review prepares an overview for the researchers to choose the types of nanoparticles to be added in the printing of the products depending on the targeted application. With the added functionality of the 3-D polymer nanocomposites, it will help in widespread of the application of 3-D printing technology in various sector.
\end{abstract}

Keywords Additive manufacturing $\cdot$ Nanoparticles $\cdot$ Incorporation $\cdot$ Printer $\cdot$ Additives

\section{Introduction}

Additive manufacturing or 3-Dimentional (3-D) printing has become popular lately. Most people are not aware that this technology has been invented way long before the 2nd millennium. 3-D printing has begun in the late 1980s whereby the first technique was known as the Rapid Prototyping (RP), or commonly recognized as Stereolithography (SLA) in the current term. The patent of this printing technique owned by an American developer named Charles Hull [1]. SLA printer was the first device to print an object directly from a

Yang Chia-Yan Evyan evyan26@gmail.com

1 Faculty of Engineering, Science and Technology, Nilai University, 71800 Nilai, Negeri Sembilan, Malaysia

2 Bioresource \& Biorefinery Laboratory, Department of Applied Physics, Faculty of Science and Technology, University Kebangsaan Malaysia, 43600 Bangi, Selangor, Malaysia computer (digital) file. 3-D printing only used in industries but not in the public when it started in 80s. This is due to 3-D printing offered a rapid prototyping of industrial products resulted in quick and accurate processes.

The design by 3-D printing is high in accuracy, it also accomplishes design freedom where there are no barriers to the imagination. Due to this advantage, artists can now produce a physical sculpture which would otherwise be sketched on a paper. With many advantages, there are more industries are shifting from conventional manufacturing to 3-D printing technique to produce their goods. The cost of production can be reduced because a few parts can be printed into one single object compared to conventional manufacturing which only enables printing of several parts separately in addition with no tooling required [2, 3]. Therefore, this favours the manufacturing industries since saving cost could mean gaining more profit. In addition, 3-D can also print parts with complex geometries which is impossible to be produced by the traditional method [4]. This will bring advantages to the manufacturers as it is possible to 
produce a wide range of industrial goods such as hard tooling product like moulds. Traditionally, moulds are computer numerical control (CNC) milled either undergoing multiple design alterations, or taking weeks and months to achieve the final design. Now, 3-D printing technologies can be used instead, allowing material and waste reduction, while improving the functionality of a mould. The main improvements which can be seen in tooling products are lightweight, improved design, improved ergonomics and reduction in material waste [5]. Due to the popularity of additive manufacturing, 3-D printers are currently used as home use by people who are interested in creating their own prototypes.

The technology is commonly used in automotive, architecture, healthcare, entertainment and goods industry. For example, the printing of spare parts is now possible with improved mechanical properties when using nanomaterial or composites. This can result in a stronger build-in which increases the safety aspect of the mobile in car racing and even space mission. Furthermore, 3-D printing technology can be applied in the medicine field. One of the successful examples is the printing of hearing aids which has a unique structure between different individuals [6, 7]. In addition, people are getting 3-D printed teeth which is customized to each person. Unlike the previous one-size-fits-all teeth which is uncomfortable, the 3-D printed teeth will fit nicely suited to the patients. This technology was also greatly explored in bioprinting of tissues and organs, the printing of animal tissues for drug testing and teaching purpose, skin grafting [8-11]. In combating the COVID-19 pandemic, 3-D printing shown its important role in coping up to produce medical equipment such as face shield, face mask, ventilator parts, nasopharyngeal swab, antibacterial mask and wearable device for patient [12-15, 170]. In addition, 3-D printed food can also be customized to patients suffering from dysphagia phenomenon to make food more visually appealing $[16,17]$. There is still a wide application of 3-D printing yet to be explored. 3-D printing is a promising technology to print customized and high-quality products. It is believed to bring positive impacts to various sectors in the future when more fields are utilising this technology.

However, the major drawback of producing 3-D printed goods is the fragility of the printed parts, as most production only focus on building prototypes rather than functional parts, since the printed objects always result in a lack of strength. Therefore, one of the promising solutions is to incorporate nanoparticles or fillers into the polymer to strengthen the printed object. Nanoparticles (NPs) are extremely tiny particles which have the size ranges from 1 to $100 \mathrm{~nm}$ [18]. Owing to their small size, nanoparticles have a large surface area to volume ratio which enable them to be explored in various sector. Aside from the application stated in the previous paragraph, researchers are aiming to produce a more functional object by the incorporation of nanoparticles. Most of the published review papers only discuss on the 3-D printing techniques and printing of pure materials. When 3-D printing technology was greatly explored in many sectors, a more functional prototypes are demanded and many researchers have been putting effort to develop composites with improved functionality and performance [19-22]. Therefore, this review provides an overview of the improvement and advancement in 3-D printing product which enhanced with nanoparticles. In Sect. 2, the types of 3-D printer are reviewed as the type of printers considered as a factor that influence the choice of raw materials to be printed, along with the advantages and disadvantages of each printing technique. The base materials that are commonly used in 3-D printing are analysed in Sect. 3 depending on the application accordingly. Last but not the least, the development of nanocomposites in various applications are reviewed in Sect. 4, followed by the discussion on the drawbacks that occurred and the suggestions for future steps of additive manufacturing in Sect. 5.

\section{Types of 3-D printer}

Overall, the 3-D printers can be classified based on printing materials and mechanism of printing. The factors that are to be considered in the 3-D printer invention are cost, printing quality, capability of printer, printing speed, expectation of users and practicality. One may keep balance among the factors during the selection of printers, for instance, you can choose Digital Light Processing (DLP) when the printing of raw material is a polymer which is high in resolution and produced in short duration, meanwhile you can select Fused Deposition Modelling (FDM) which is much lower cost compared to FDM. The types of 3-D printers with their respective advantages and disadvantages are summarized in Table 1.

In additive manufacturing, stereolithography (SLA) being the most popular used 3-D printing technology, is able to provide high accuracy with a smooth surface finish and therefore is it very suitable in producing prototypes. However, this type of printer is considered expensive due to the material used which is a liquid resin that cost $\$ 50$ to $\$ 400$ per litter [36]. As an alternative, Fused Deposition Modelling (FDM) may be preferable as it is lower in cost than other 3-D printing technologies and it is even convenient at home usages. However, FDM 3-D printer can only supports thermoplastic materials. Furthermore, Selected Laser Sintering (SLS) is also a good choice as it can build objects with complex geometries. The main advantage of using SLS printer is that no additional supports are required in the printing process which results in lesser material waste and no post processing is required in the printing process like other 3D printing technologies. However, the final object 


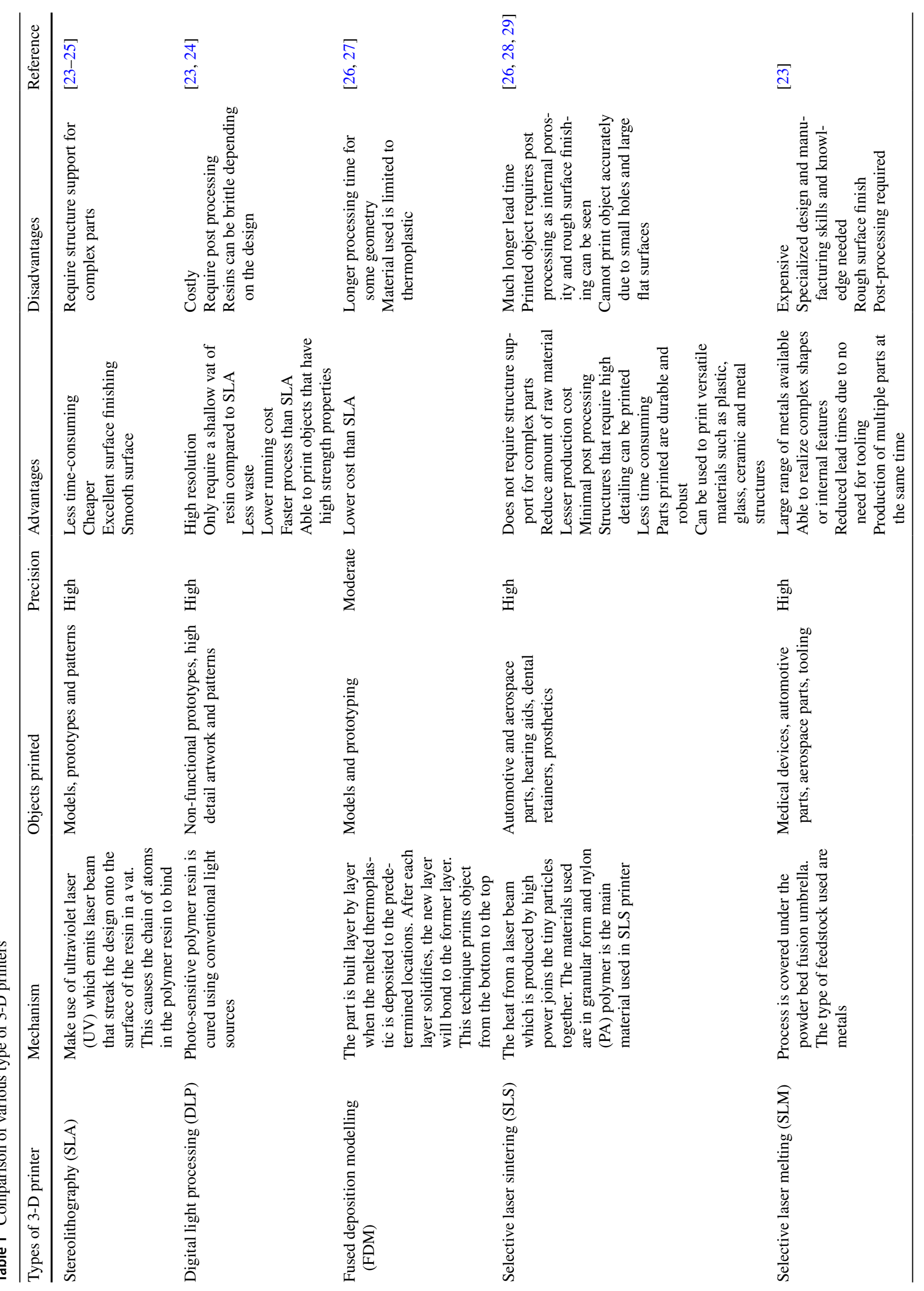




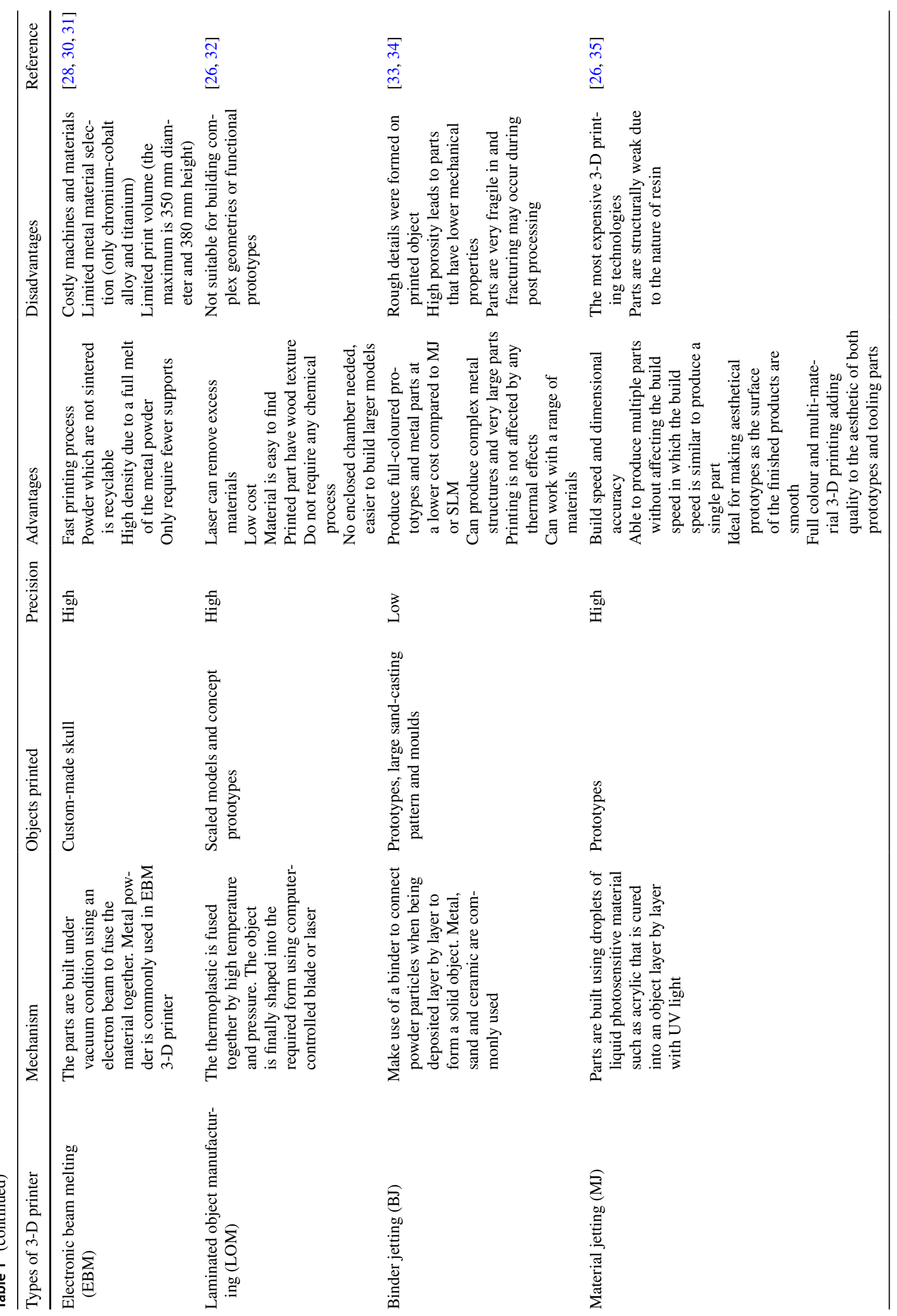


may not have an accurate measurement and the surface finish is slightly rough. The Laminated Object Manufacturing (LOM) is an ideal choice for non-functional prototype and the process is cheap because of the material used is mainly paper. The main disadvantage is that the object printed will have low accuracy and low strength as the surface is not fined due to the wood-like texture. In addition, it also requires additional procedures of post-printing.

Commonly, all the 3-D printers have characteristics which are similar even though they might be different from mechanism, materials and applications. All the 3-D printers consisted of a 3-D modelling application or a scanner followed by a structure designing. Besides that, the design of a structure is needed to be saved in Computer-Aided Design (CAD) form and sliced before sending to the 3-D printer to print the object [26]. The process of additive manufacturing is simplified in Fig. 1. In general, all 3-D printers work similarly. Firstly, a designed 3-D model will be converted into a printable file known as STL file. With a slicing software, the structure will be sliced into hundreds or thousands of layers which is ready to be printed using a 3-D printer. This sliced STL file will then be printed layer by layer manner in the 3-D printer into a prototype or product.

\section{Base materials in 3-D printing}

There are few types of materials that commonly used most of the printing materials are malleable materials or materials with high permeability and plasticity. The main advantage of using plastic in 3-D printing are low cost and light weight. In the application of 3-D printed nanocomposites, a polymer is preferred to hold the nanoparticles because the dispersed form of nanoparticles requires a later separation which increases the process cost since not all powders can be revived.

\subsection{Polymer/plastics}

Most of the consumer products are made primarily using thermoplastics. Plastics have been used in 3-D printing widely to create consumer products as well as prototypes.
Table 2 summarizes the thermoplastic or polymers used in 3-D printing.

In the application of 3-D printing in tissue engineering, the polymers used may be different from what is used in normal 3-D printing uses. Since biocompatibility is an important aspect in the applications in the medical field, the choice of polymer is important. The choices of polymer used in 3-D printing in the medical sector are categorized into the natural polymer, synthetic polymer, bioceramic, metal-based polymer and biocomposite [49].

To produce a natural polymer as the material for 3-D printing, biological materials such as collagen, polysaccharides, gelatin, etc., was used to form a scaffold. One of the biggest advantages of using natural polymer is that the host tissue's extracellular matrix can be maintained [49] and low possibility of immune rejection reaction [50]. However, natural polymers often lack in mechanical strength hindering their applications that requires load-bearing. In addition, it also degrades in a fast pace that the healing tissues were lacking support. Therefore, the use of synthetic polymer is a better choice to support tissues for their biodegradable, enhanced mechanical properties and increased degradation period. Some of the examples of synthetic polymers are poly(lactic acid) (PLA), poly(lacti-co-glycolic acid) (PLGA) and poly(glycolic acid) (PGA) [51].

Hydroxyapatite (HA) and Beta tri-calcium phosphate $(\beta$-TCP) which are categorized under bioceramic materials are also widely used in 3-D printing especially in bone tissue engineering because of its desirable properties such as biocompatibility, physically and chemically stable and antibacterial effect $[52,53]$. Despite having numerous advantages, bioceramics often suffer from drawbacks due to high stiffness, fractures and low elasticity [49]. This had hindered its clinical application. Hence, it was suggested that bioceramics can be combined with other raw materials to produce an ideal scaffold.

Metal-based polymers, on the other hand, is useful especially in substituting bone in the human body. It has a strong mechanical strength, able to support tissue ingrowth and corrosion resistant. Titanium (Ti) alloy is suitable in the use of bone, hip, femur, skull, and knee replacement as it is strong and biocompatible. But the use of metal-based polymers may also be complicated due to poor bioactivity on the metal
Fig. 1 Process of 3-D printing from design to printing [23]

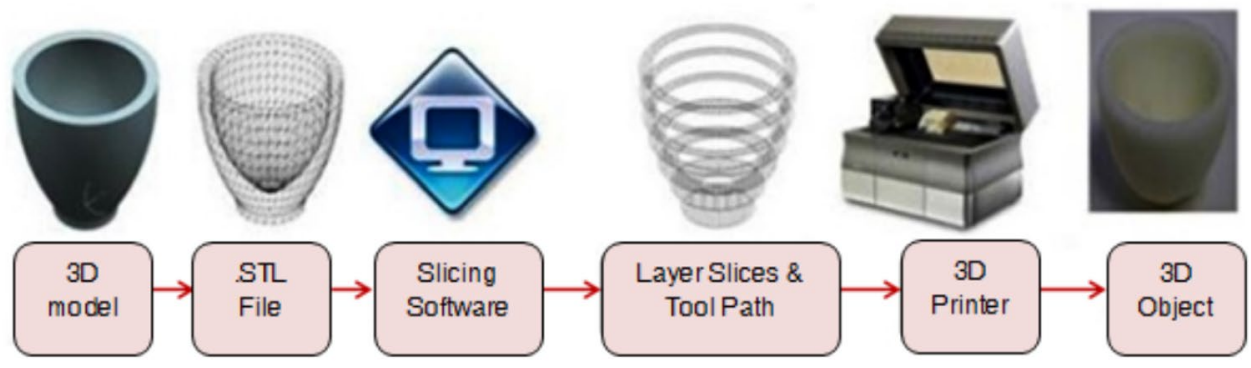




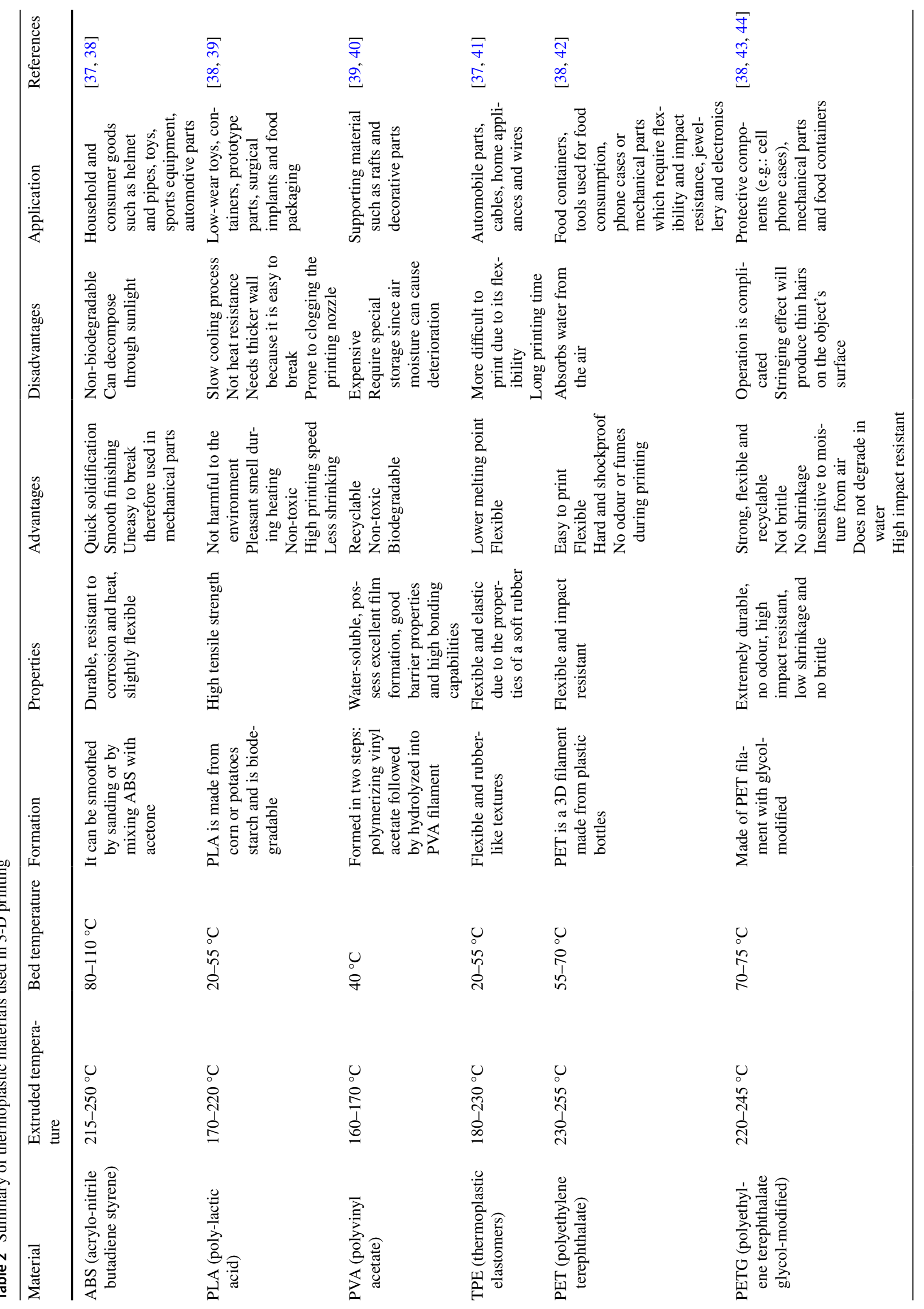




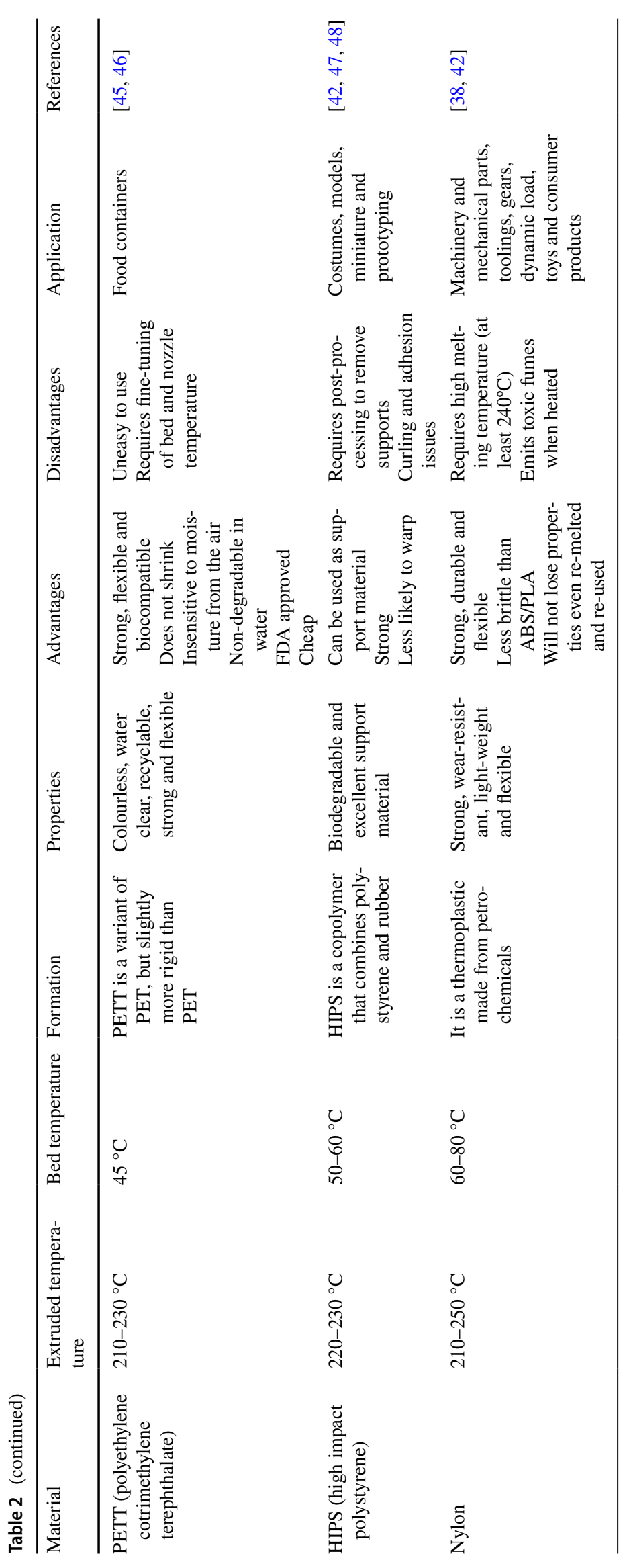


surface, non-biodegradable and possible discharge of toxic due to wear.

Every polymer has its own limitations, biocomposite is the solution to produce an ideal scaffold in medical applications. A biocomposite is meant by incorporating nanosized or micro-sized to reinforce the material. For example, polycaprolactone (PCL) which is a synthetic polymer is mixed with $\beta$-TCP which is a bioceramic polymer and phlorotannins which is a marine algal polyphenol to produce a bone tissue regeneration scaffold. In this scaffold [54]. PCL plays a role as a matrix to support structural stability and offers pore structure. Whereas, $\beta$-TCP is responsible for the absorbability and osteoconduction. Phlorotannins were added into the matrix as an antibacterial, antioxidant and antiallergic agent [55]. This scaffold was successfully printed using extrusion-based 3-D printer. The resulting scaffold displayed a rise in cell viability and proliferation.

In the application of water treatment, $\mathrm{TiO}_{2}$ nanoparticles as catalyst in embedded form are more sustainable because it is reusable and recyclable [56]. This is because nano-sized particles are difficult to separate which results in non-reusability and increase in overall cost. For example, Rosenau and the team had embedded $\mathrm{TiO}_{2}$ nanoparticles into a cellulose membrane for photocatalytic decomposition of dyes [57].

\subsection{Metals}

Metals are sometimes used in 3-D printing due to their good strength and thermal properties. They can be used to print objects which need to withstand load such as aerospace parts and automobile parts. The summary of metals used in 3-D printing is shown in Table 3.

In comparison to the tensile strength, a mixture of cobaltchrome metal improves the tensile strength compared to other metals, making it useful to produce engine parts which requires high-stress tolerance. Most of the metals are used for functional applications rather than display applications as most of the display objects can be printed by using plastic materials. As shown in Fig. 3, titanium, maraging steel, cobalt-chrome, tungsten and nickel possesses high tensile strength that are above $1000 \mathrm{MPa}$. Tensile strength is a direct way to evaluate the mechanical properties of metals. Metals with high tensile strength are able to resist wear and tear under extreme conditions, which is especially useful in the applications of aerospace and automobile. Metal selection in the aerospace field is crucial to reduce fuel consumption, weight reduction and enhance performance [66]. Despite having lower tensile strength, aluminium is still widely used in the automotive and aerospace industry [67]. This is mainly due to its low density which resulted in lighter parts, as well as its inexpensive cost compared to other metals. To eliminate the metallurgical defects in aluminium parts, refine grain size and repair surface defects, wire + arc AM
(WAAM) hybrid-AM process can be adopted [68]. Titanium on the other hand is very costly, but it is about twice the strength of aluminium, in addition with low-density property. Tungsten metal which has anti-vibration property, is unique in its application since it can damper the vibration, making it perfect to produce flight blades, ballast weight, missile components and more.

\subsection{Ceramics}

Ceramics have excellent properties such as low density, strong, high electrical insulating capability, resistant to corrosion, chemical stability and dimensional stability. Therefore, these properties make them suitable to be applied in a wide range of applications. This includes the chemical industry, biomedical engineering, aerospace and machinery. These properties allow it to be applied in many fields as stated previously. Through traditional method, gel casting and moulding techniques are used to form the shapes. The powder can be added with or without the binders and other additives. To achieve densification, it is compulsory to sinter the green parts at high temperature. Yet, these traditional ceramic forming techniques have limitations due to the long processing time along with the high cost. In addition, it is also impossible to produce structures with interconnected holes and highly complex geometries with moulding technique. Besides, machining of ceramic components is another issue as the cutting tools are subjected to severe wear and defects in the ceramic object due to extreme hardness and brittleness. Therefore, it is difficult to achieve dimensional precision and fine surface finishing. The problems arose through traditional technology could be addressed by the replacement of 3-D printing technology.

The technology can be classified into slurry-based and powder-based methods in accordance to the form of the preprocessed feedstock. For slurry-based ceramic feedstock, the fine ceramic particles are dispersed in a liquid or semiliquid system. Depending on the viscosity, the liquid is in the form of inks whereas the semi-liquid is in the form of and the solid loading of the system [69]. For this feedstock, Selective Laser (SL), Digital Light Processing (DLP), Twophoton Polymerization (TPP), Inkjet Printing (IJP), Direct Ink Write (DIW) and Binder Jetting (BJ) can be used to print the object [70]. On the other hand, powder-based ceramic feedstock employ powder beds that contain loose ceramic particles as feedstock. Ceramic particles can be bonded by powder fusion using thermal energy from the laser beam or spreading the liquid binders [69]. The types of 3-D printer used for this feedstock are Selective Laser Sintering (SLS) and Selective Laser Melting (SLM).

As mentioned earlier, green parts are created in ceramic 3D printers. The initial process is similar to standard 3-D printing process, which is slicing of designed object in a 


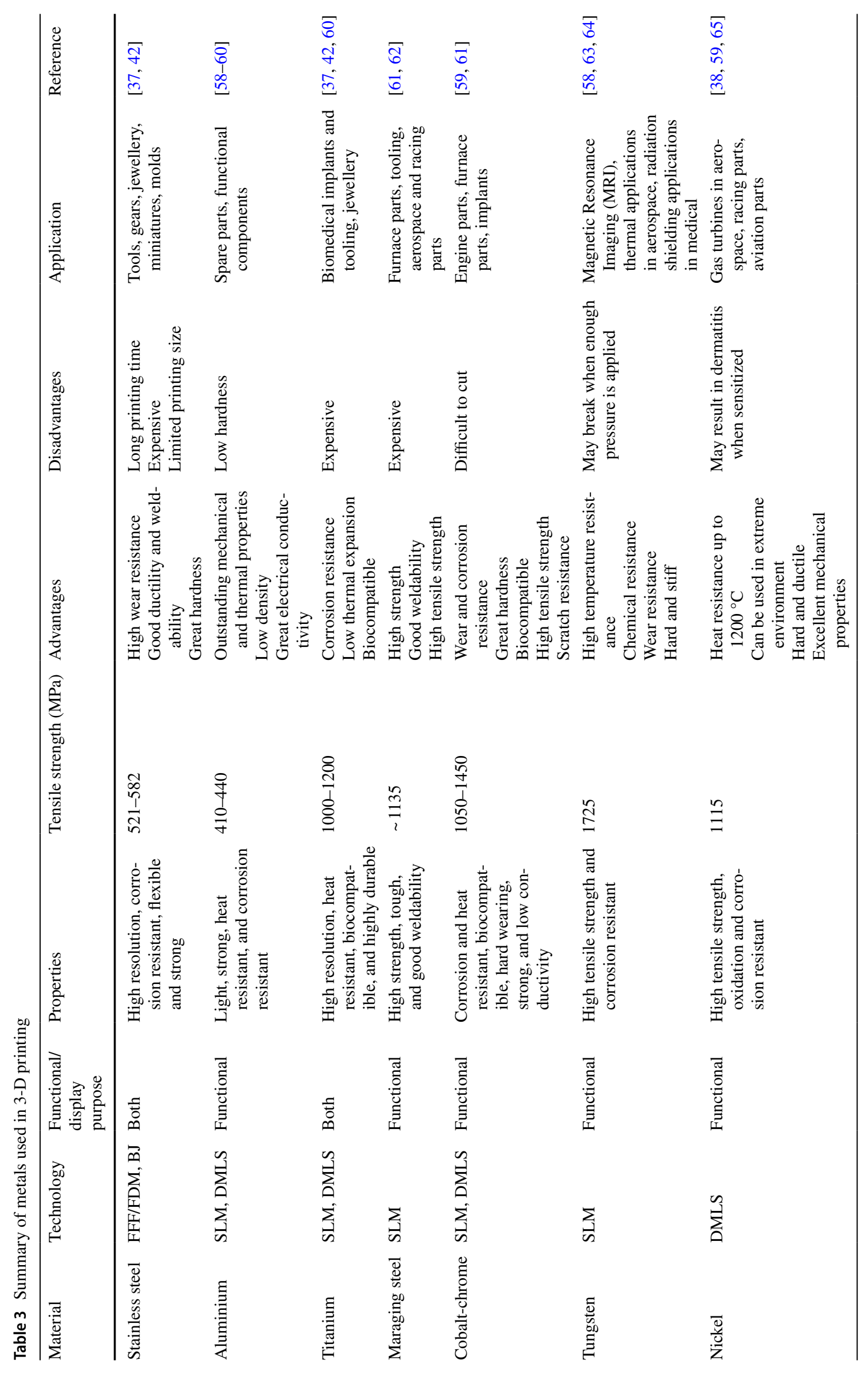


slicing software until it is ready to undergo 3-D printing. For ceramic 3-D printing, additional treatments are required to treat the green state of the object, since the object is fragile and brittle at this stage. These green parts will go through various stages to reach their final structure which are glazing and firing to form a stronger ceramic end-product. For instance, the bending strength of the ceramic prototype significantly increased from $17 \mathrm{MPa}$ for green state to $220 \mathrm{MPa}$ for the final prototype [71]. The process is illustrated in Fig. 2.

\section{Development of 3-D printed nanocomposites}

To commercialize products made with 3-D printing technology, it is not yet possible since 3-D printing has a major drawback in strength ability and functionality. 3-D printed objects are often fragile, restricting its application in various fields. To overcome these limitations, reinforcements can be achieved by merging the matrix and composites to produce a more useful product which are not attainable by using the matrix alone. In this section, the incorporation of nanoparticles into the polymer matrix will be discussed.

\subsection{Composites}

A composite material is a material created with two or more basic materials which own different physical and chemical properties. They display characteristics that are different from each individual component when they are combined. This gives them a better advantage over more traditional thermoplastics used in 3D printing like ABS or PLA. The applications of 3-D printing can be expanded with these additional materials and the properties. They are similar as nanocomposites in terms of mixing two or more different materials together, but they are also different in terms of the size of the particles incorporated. A composite does not matter the size of the particles incorporated or mixed as long as the materials are compatible to be printed. The summary of composites material is shown in Table 4.

Besides the above composites material, polylamide (nylon) and polycarbonate (PC) are also an interesting material to be explored. Both are categorized as thermoplastics but with an exceptional function where it can substitute low-strength metals. In some circumstances, thermoplastic polymers are preferred over metals due to their light weight, low cost, does not require lubrication, silence and efficient [80]. Therefore, it is suggested that these thermoplastics can be used to produce a composite material for 3-D printing. For example, nylon when mixed with chopped carbon fibers produces chemical and heat resistance along with high strength properties [80-84]. The tensile strength increased to $\sim 6$ times higher than non-reinforced polymer $[81,82]$.

Polycarbonate (PC) on the other hand, is commonly appeared as a transparent plastic. Compared to nylon, this material is more durable and stronger [81]. This material has almost the same internal transmission of light as glass, making it suitable to be used as plastic lenses in eyewear, digital disks, automobile parts, greenhouse etc. This material with excellent heat resistance is also not east to degrade when exposed to high temperature. It is important to note that applications which require high transparency and high impact resistance can consider this material in their usage.

\subsection{Nanoparticles as additive in composite}

The addition of nanoparticles into an additive is known as nano-additive. Nanoparticle is an ultra-small particle with the size between 1 and $100 \mathrm{~nm}(\mathrm{~nm})$ in diameter. Macrosized materials often give rise to problem with voids or cracks in the 3-D printed structure, which causes the structure to be fragile and unsuitable for many usages. By integrating the mechanical properties of nanoparticles into the macro structure will provide a new application in various fields, where nanoparticles are able to reduce friction and wear between two surfaces, form an anti-wear film, provide a mending effect to compensate for the loss of mass and reduce surface roughness [78]. Nanoparticles (NPs) can be categorized into carbon-based NPs, metal-based NPs, magnetic-based NPs, ceramic-based NPs, semiconductor-based NPs, polymeric NPs and lipid-based NPs [77]. In the advancement of 3-D printing, carbon-based NPs, semiconductor-based NPs and metal-based NPs are most commonly explored as an additive for the polymer material. Commonly, the synthesis of nanocomposites had problem
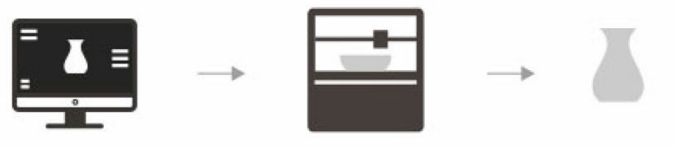

3D modeling

Green state

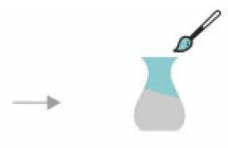

Glazing

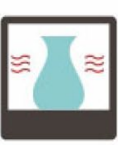

Firing

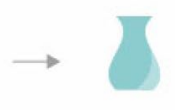

Finished product

Fig. 2 The ceramic 3-D printing process [72] 
Table 4 Summary of composite material used in 3-D printing

\begin{tabular}{|c|c|c|c|c|c|}
\hline Type of composite & Conductive & Metal/plastic filament & Alumide & Wood/plastic filament & Sandstone \\
\hline Contents & $\begin{array}{l}\text { PLA/ABS and gra- } \\
\text { phene }\end{array}$ & $\begin{array}{l}\text { Bronze/steel/copper/ } \\
\text { iron and PLA }\end{array}$ & $\begin{array}{l}\text { Polyamide and alu- } \\
\text { minium powder }\end{array}$ & $\begin{array}{l}\text { Wood fiber sheets and } \\
\text { resin }\end{array}$ & $\begin{array}{l}\text { Fine chalk powder and } \\
\text { PLA }\end{array}$ \\
\hline Added-value & $\begin{array}{l}\text { Create conductive 3-D } \\
\text { objects } \\
\text { Flexible }\end{array}$ & $\begin{array}{l}\text { Object printed have } \\
\text { the optical properties } \\
\text { of the metal incor- } \\
\text { porated } \\
\text { The printed object is } \\
\text { heavier than thermo- } \\
\text { plastics alone }\end{array}$ & $\begin{array}{l}\text { Objects printed have } \\
\text { excellent size accu- } \\
\text { racy } \\
\text { Tough and suitable for } \\
\text { long term usage } \\
\text { Suitable for post-pro- } \\
\text { cessing techniques } \\
\text { like coating or } \\
\text { polishing }\end{array}$ & $\begin{array}{l}\text { Can create wood-like } \\
\text { prototypes } \\
\text { The shade of brown } \\
\text { can be adjusted } \\
\text { according to the } \\
\text { extrusion tempera- } \\
\text { ture }\end{array}$ & $\begin{array}{l}\text { Can create stone-like } \\
\text { prototypes }\end{array}$ \\
\hline Technology & FDM & FDM & SLS & FDM & BJ \\
\hline Application & $\begin{array}{l}\text { DIY projects, touch } \\
\text { sensors such as MIDI } \\
\text { machines and gaming } \\
\text { pads, and conductive } \\
\text { traces in wearable } \\
\text { electronic devices }\end{array}$ & Visual arts & $\begin{array}{l}\text { DIY projects, func- } \\
\text { tional prototypes, } \\
\text { and manufacturing }\end{array}$ & $\begin{array}{l}\text { Conceptual models, } \\
\text { visual arts }\end{array}$ & $\begin{array}{l}\text { Architectural, structural } \\
\text { parts, landscape and } \\
\text { museum display }\end{array}$ \\
\hline Properties & Conductive & Metallic & $\begin{array}{l}\text { Strong, heat resistant, } \\
\text { and high resolution }\end{array}$ & Fragile & $\begin{array}{l}\text { Unique sandstone } \\
\text { appearance }\end{array}$ \\
\hline References & {$[3,73]$} & {$[16,74]$} & {$[17,75]$} & {$[76,77]$} & {$[78,79]$} \\
\hline
\end{tabular}

with inhomogeneity which affects the number of additives that can be incorporated into the matrix.

In general, the incorporation of nanoparticles into the polymer will affect the structure's porosity, pore size, membrane pore structure, surface charge, surface roughness and mechanical strength [85]. The applications of various types of nanoparticle are demonstrated in Table 5.

\subsubsection{Carbon-based nanoparticles}

Carbonization, grinding, heating and activation are methods that are used to produce nano-sized carbon [86]. Carbon-based NPs are popular and they are widely in the various field due to their exceptional mechanical, thermal, optical, and physical properties. They also possess high boiling and melting point above $3500{ }^{\circ} \mathrm{C}$ [86]. Carbon quantum dots, graphene and carbon nanotubes (CNTs) are categorized under carbon-based nanoparticles. This type of nanoparticle is widely explored in research because they have good electrical conductivity, mechanical properties, heat conductivity, stable and low toxicity [87]. A study showed that carbon filler reinforced with nylon achieved a tensile strength of $700 \mathrm{MPa}$ and 68GPa for tensile modulus [83]. In addition, embedding carbon fibers can further strengthen the polycarbonate to expand its applications in 3 -D printing. Espalin and the research team had incorporated carbon fibers into the $\mathrm{PC}$ polymer to design a composite which has higher mechanical strength [88]. Compared to PC polymer alone, the tensile strength increased by $77 \%$. The SEM result also showed that reduction of porosity happened when carbon fibers was reinforced [88]. Another reinforcement of carbon fibers into Polycarbonate/ Acrylonitrile butadiene styrene (PC/ABS) was reported to have minimum wear rate and high mechanical strength [89].

They are most commonly used in the energy storage field. It is a well-known material to be used in capacitors, batteries and fuel cell components. Since human body consist of carbon, carbon-based NPs are also biocompatible with human cell. Graphene nanoparticles are used in drug delivery to deliver drugs to the targeted cancer cells. Compared to activated carbon, CNTs are ideal in removing both organic and inorganic wastes in water purification due to their hollow structure, high surface area and strong adsorption affinity towards organic wastes such as dye, pesticides, phenols, benzene and carbon $[85,90]$. It was also proposed that electrochemical reaction of CNTs can be further improved by doping metal or non-metal to the CNTs [91]. For example, doping iron $(\mathrm{Fe})$ on CNTs improved the degradation efficiency of beta-blocker metoprolol from 74 to $97 \%$ due to the triggering of oxidative species [91]. In another research, $\mathrm{TiO}_{2}$ was doped onto CNTs to improve the reduce the band gap and photocatalytic performance in wastewater treatment since CNTs are able to expand the light response to visible light that would otherwise sensitive to UV alone if using bare $\mathrm{TiO}_{2}$ [92]. In addition, CNTs are unique because no other material has a mixture of physical, chemical and mechanical properties like CNTs [93]. Compared to metals such as copper and aluminium, CNTs possess both excellent electrical and thermal conductivity, lightweight, with acids 


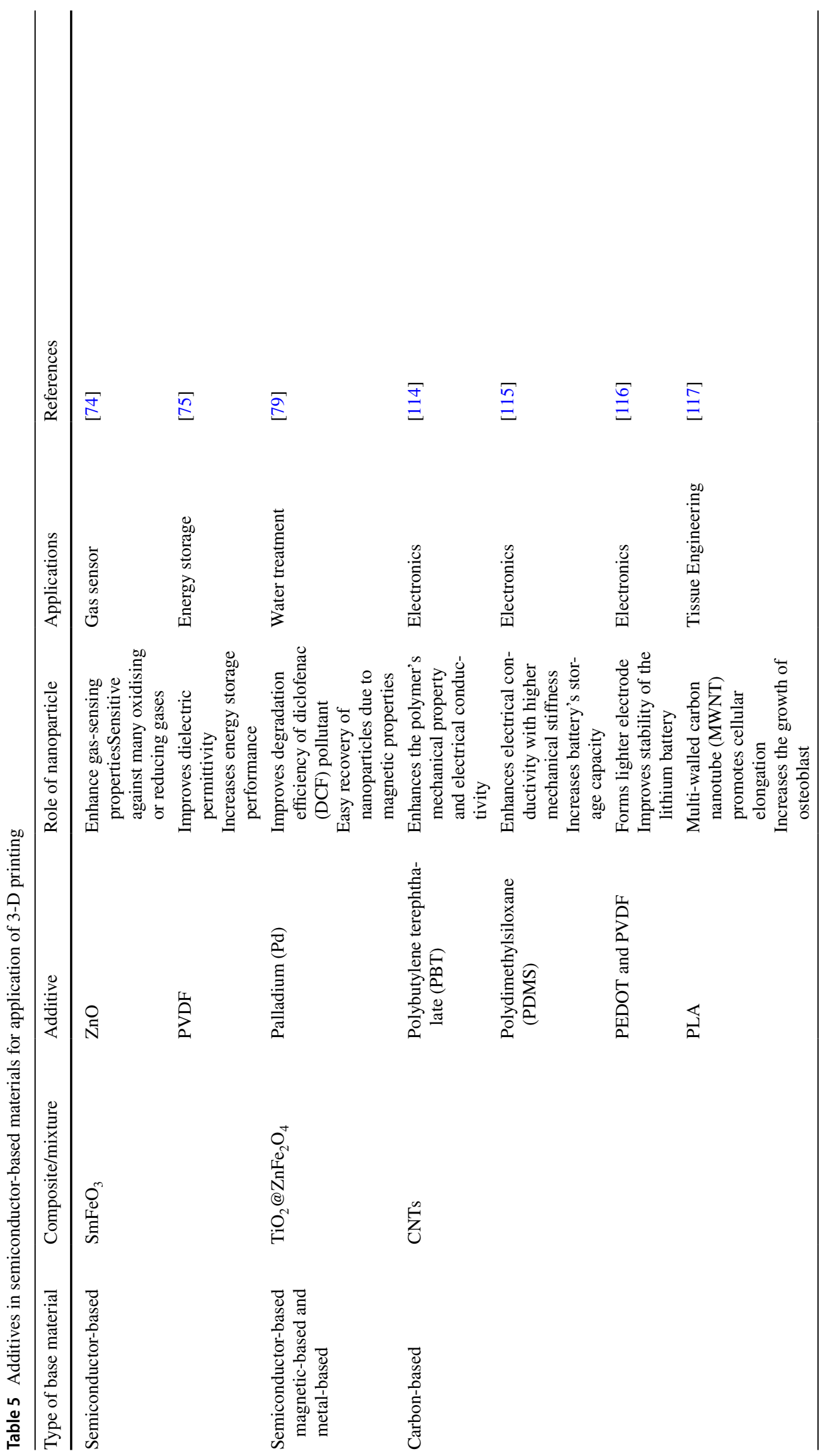




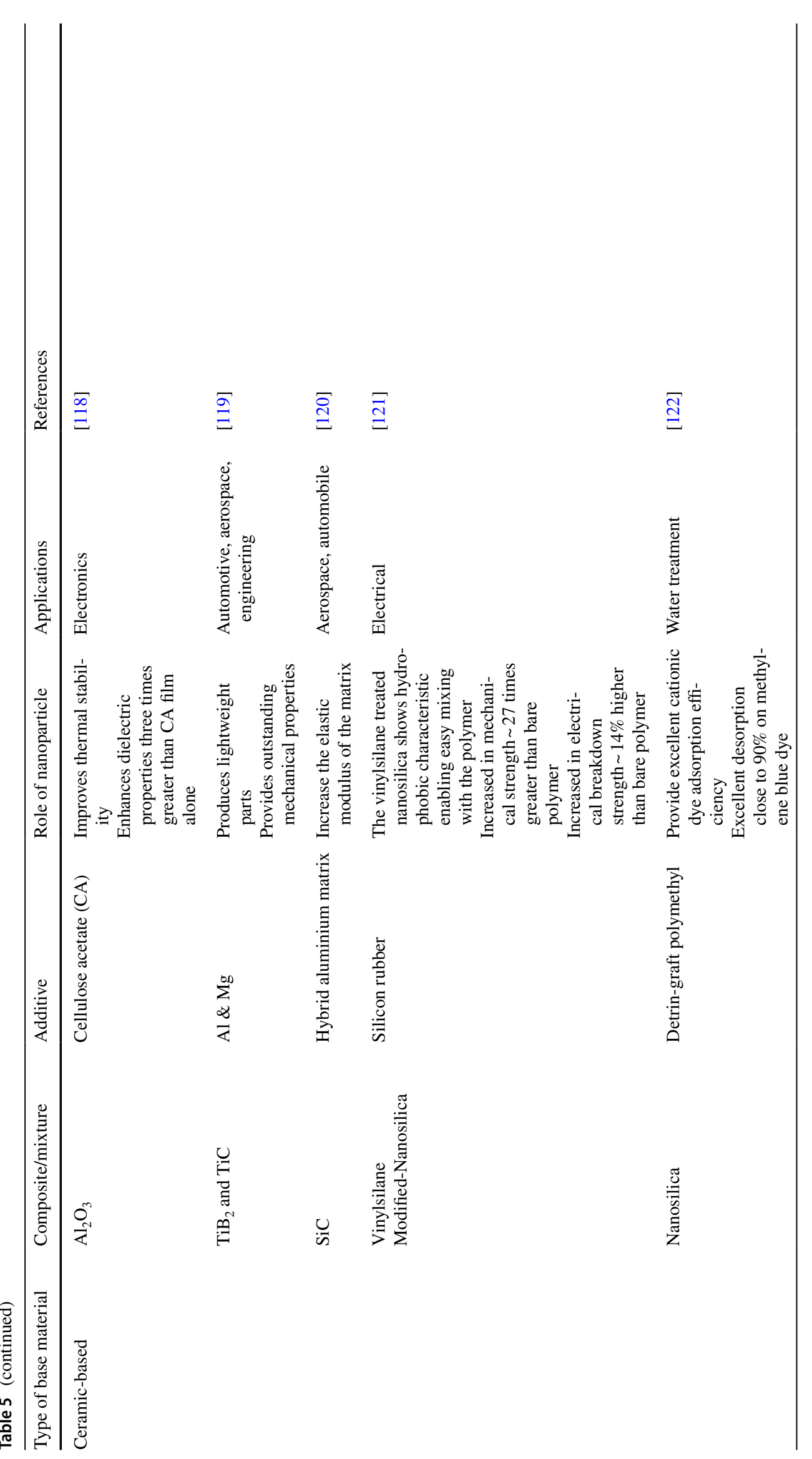




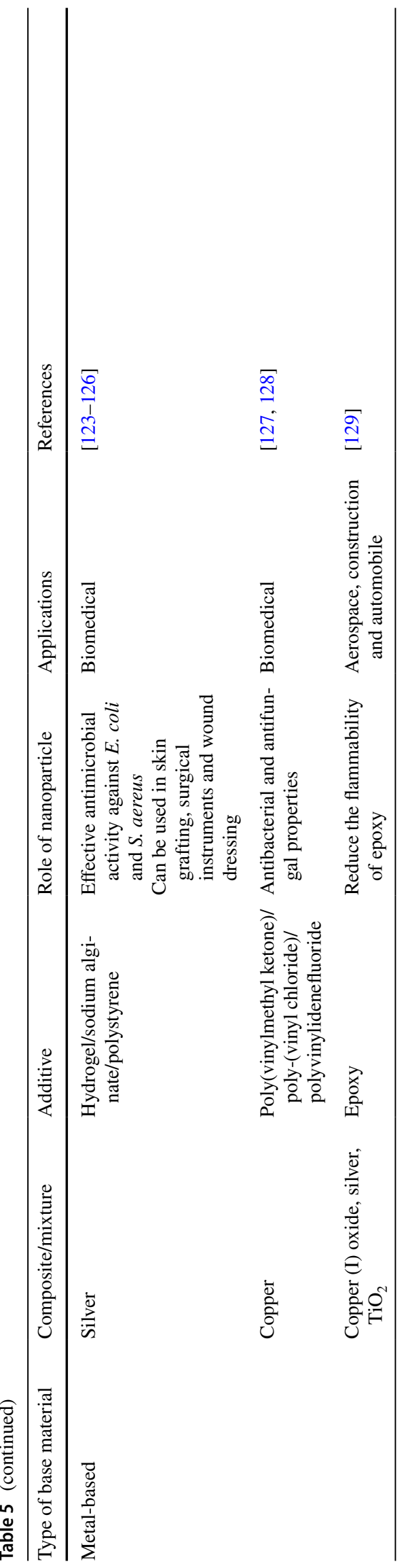

and bases resistant [93, 94]. Hence, doping of CNTs will benefit the 3-D printed product in enhancing the removal of contaminants in wastewater treatment application.

\subsubsection{Ceramic-based nanoparticles}

This type of nanoparticles is chemically inert, possess high heat resistant, low electrical conductivity, resistant to corrosion and high stiffness [95]. Some of the examples are hydroxyapatite (HA), alumina $\left(\mathrm{Al}_{2} \mathrm{O}_{3}\right)$, titanium dioxide $\left(\mathrm{TiO}_{2}\right)$, silica, silicon carbide and silicon nitrite [96, 97]. They own properties between metal and non-metal. Compared to carbon nanoparticles, they have lower electrical and thermal conductivity, but they are high in stiffness, elastic modulus and resist to corrosion [95]. To describe the addition of ceramic-based nanoparticles as additive, the tensile strength and tensile modulus were reported in Ahuja's research team as 44.52 $\mathrm{MPa}$ and $871.81 \mathrm{MPa}$ respectively when aluminium oxide $\left(\mathrm{Al}_{2} \mathrm{O}_{3}\right)$ was reinforced with nylon [98]. Ceramic nanoparticles are produced via wet-chemical process, or commonly known as sol-gel method that involves a sol (chemical solution) and a gel (precursor) to produce an oxide which is a type of ceramic [99]. The excess solvents will be evaporated and the final product is a solid form. They are widely used in photocatalysis, bone tissue engineering, imaging and drug delivery. Titanium dioxide $\left(\mathrm{TiO}_{2}\right)$ is most widely applied in photocatalysis due to their outstanding photocatalytic performance, non-toxicity, chemically stable and low cost. Despite their numerous benefits in photocatalysis, the large band gap is the main limitation of $\mathrm{TiO}_{2}$ nanoparticles disabling it to perform well under natural light source (visible light). In recent research, most studies focus on doping $\mathrm{TiO}_{2}$ with other elements. For instance, iron-8-hydroxyquinoline-7-carboxylic (Fe-HQLC) as a composite for $\mathrm{TiO}_{2}$ nanoparticles shifted the absorption towards visible light. It was concluded that phenol was degraded up to $99 \%$, antibiotics ciprofloxacin (CIP) and tetracycline (TC) was degraded to almost $97 \%$. In another report, doping nitrogen $(\mathrm{N})$ with $\mathrm{TiO}_{2}$ significantly increased the photocatalytic performance under UV and visible light [100]. Undoped $\mathrm{TiO}_{2}$ only accounts for $87 \%$ and $45 \%$ degradation on furfural under UV and visible light respectively. When nitrogen was doped with $\mathrm{TiO}_{2}$, the photocatalytic performance of the photocatalyst reached $97 \%$ and $79 \%$ under UV and visible light respectively [100].

Commonly, hydroxyapatite, tricalcium phosphate and calcium silicate are applied in bone tissue engineering owing to various advantageous properties including biocompatibility, flexural strength, non-toxicity to cells and enhance cell proliferation [101, 102]. A bone scaffold can be categorized into bioinert scaffold and bioactive scaffold. Alumina $\left(\mathrm{Al}_{2} \mathrm{O}_{3}\right)$ and zirconia $\left(\mathrm{ZrO}_{2}\right)$ are examples of bioinert scaffold. They are chemically inert and hence will not have tissue reaction. They 
are also biocompatible, tough and corrosion resistant. In contrast, bioactive scaffolds are able to regenerate damaged or lost tissues. Common bioactive scaffolds that are used in bone tissue engineering are beta-tricalciumphosphate (b-TCP), calcium silicate (CS), hydroxyapatite (HAP) and bioactive glass (BG). In drug delivery applications, hydroxyapatite are widely explored. They are exploited to treat cancer cells as a drug carrier. One of the main features of HAP is it is able to prolong the release of drugs to the target tissue [103]. However, the extension of drug release time can be prolonged further by doping. For example, iron $(\mathrm{Fe})$ has been doped onto HAP showed an enhancement in biocompatibility and longer drug release time [104]. Besides, HAP is also explored in arthroplasty by slowly releasing vancomycin to treat serious infection and a direct way [105].

\subsubsection{Metal-based nanoparticles}

Metal-based nanoparticles are derived from metal precursors. They are a good heat and electrical conductor $[95,106]$. However, they are prone to corrosive damage. By using metalbased nanoparticles as additive in polymer material, it is able to improve the mechanical strength of the desired material. Masood and Song reported the reinforcement of nylon with iron give rise to the tensile strength and tensile modulus by 3.87 MPa and 54.52 MPa respectively [107]. Due to its antimicrobial property, colloidal metal nanoparticles have also received much attention. For example, silver $(\mathrm{Ag}) \mathrm{NPs}$ have excellent cytotoxicity towards a wide range of bacteria and fungi [108]. Likewise, copper (Cu) NPs coated on cellulose also showed effectiveness in destroying multi-drug resistant pathogen such as A. baumannii [109].

\subsubsection{Semiconductor-based nanoparticles}

Semiconductor-based nanoparticles are unique because they own properties of metal and non-metal [110]. To modify the physical and chemical properties of a semiconductor nanoparticle, the size is the key factor that results in the unique properties of the nanoparticles [110, 111]. When the size changes, the conductivity and the optical properties will be modified. It is applied in various field such as catalyst, electronics, solar cells, LED, automobile, etc. The widening of band gap in semiconductor nanoparticles enables materials to operate at high temperatures [112]. Overall, the need for excess wires and cooling systems can be eliminated in a system such as fuel combustion. The elimination of excess material will reduce the complexity of the system and weight, in addition with improved thermal stability.

\subsection{Nanoparticles in improving biological properties}

In a study related to cartilage regeneration, Zhang and the team had proposed a scaffold-based technique to replace the traditional surgical process which is complex and requires long recovery time [113]. Scaffold-based technique such as 3-D printing is beneficial because it can reduce doner site complications, shorter recovery time and requires fewer procedures [113]. In this study, PEGDA hydrogels incorporated with nanoparticles containing growth factors was printed into a cartilage model to grow human mesenchymal stem cells (hMSC) via cold atmospheric plasma (CAP) technique. $\mathrm{CAP}$ is an effective way to alter materials to create environments favored by cells to enhance cell proliferation and cell attachment [113]. Whereas, the nanoparticle poly(lactic-coglycolic) (PLGA) was loaded with bovine serum albumin (BSA) or transforming growth factor- $\beta 1$ (TGF- $\beta 1$ ) as the core. The scaffold was then printed using a customized stereolithography (SL) 3-D printer with three-axis motions. The printed cartilage scaffold had shown an increase in compressive strength (5.2 $\mathrm{MPa}$ ) comparing to human cartilage tissue (0.4-0.8 MPa). CAP treatment in addition with PLGA nanoparticles have shown a synergic effect in promoting cell growth and the printing of PEDGA scaffold. This proposed scaffold could be a suitable candidate to promote cartilage repair in the medical field (Table 5).

Some patients with orthopedic implant face bacterial infections from Staphylococcus aureus and Staphylococcus epidermidis after the surgery. These bacteria will attach on the surface of the implant, grow and form biofilms [130]. Biphasic calcium phosphate (BCP) nanoparticles and rifampicin (RFP) nanoparticles were incorporated into a matrix poly(D,L-lactic-co-glycolic) acid (PLGA) which is biodegradable. The differentiation of osteoblast was contributed by BCP nanoparticles whereas the killing of bacteria was caused by the RPF nanoparticles by steady-release of antibiotic [131]. This nanocomposite could be used in printing implants to avoid bacterial infections in the patient's body.

The amount of nanoparticles added into the polymer matrix will determine the physical or chemical properties of the printed object, as well as the homogeneity of the printing ink. Through the research of using metal nanoparticles (silver and copper) as additives in resin, it was found that up to $1 \%$ wt. of nanoparticles with the size of $25 \mathrm{~nm}$ and $55 \mathrm{~nm}$ respectively can be well-dispersed in the resin polymer without any sedimentation and agglomeration [132]. The nanocomposite was printed with SLA 3-D printer. By 
the addition of silver and copper nanoparticles into the polymer resin, the resistance decreased to almost $100 \%$ making this nanocomposite to be suitable for electronic applications [132]. In another research, carbon-based nanoparticle, graphene oxide (GO) was incorporated into the photopolymer at $0.2 \% \mathrm{wt}$ and printed using a SLA 3-D printer. [133]. The strength increased to $\sim 62 \%$ whereas the elongation to failure increased to $\sim 13 \%$ compared to solely polymer [133]. The incorporation of $1 \% \mathrm{wt}$. GO in photo-curable resin printed with SLA 3-D printer as well showed a significant increase in tensile strength by $~ 674 \%$ [134]. To compare the effect of adding different types of carbon-based nanoparticles into epoxy polymer, $0.1 \% \mathrm{wt}$. of pristine graphene, single-walled and multi-walled carbon nanotubes were incorporated [135]. It was found that nanocomposite containing graphene has the best enhancement as to stiffness (31\%), mechanical strength (40\%) and fracture toughness $(53 \%)$ compared to structure incorporated with other carbon-based nanoparticles [135]. At $0.125 \% \mathrm{wt}$, the fracture toughness peak reached $65 \%$ [135]. A low composition of CNT (0.04\%wt) and graphene $(0.08 \% \mathrm{wt})$ nanoparticles was demonstrated for the enhancement in electrical conductivity by sevenfolds when incorporated in PBT thermoplastics printed with FDM 3-D printer [136]. According to many researches, SLA is commonly adopted as the choice of printing nanocomposites. In addition, most researches only incorporated a low amount of nanoparticles $(\leq 1 \% \mathrm{wt})$ to improve the properties of a particular material of interest.

\subsection{The application of 3-D printed nanocomposites}

Nanocomposite involves the addition of nanoparticles with the size of $1 \mathrm{~nm}$ to $100 \mathrm{~nm}$ into a suitable polymer matrix. According to Zachary and Ghasemi, most nanocomposite researches used a comparatively large amount of nanoparticles (more than $0.1 \%$ by weight) to improve the properties of a certain material or structure [137].

\subsubsection{Electrical and electronics}

In the energy storage application, the manufacture of high dialectical energy devices is highly demanding because they can store more energy compared to those with lower dielectric constants. This is especially important in the application of capacitors, semiconductor device, liquid crystal displays (LCD), and other embedded electronics [138]. One of the advantages of incorporating nano-sized particles into the polymer is that the resulting nanocomposite will have an increment in dielectric strength since the nanoparticles have a large surface area. Besides, nanoparticles can also reduce the size of voids and hence enhancing the strength of the nanocomposites [139].

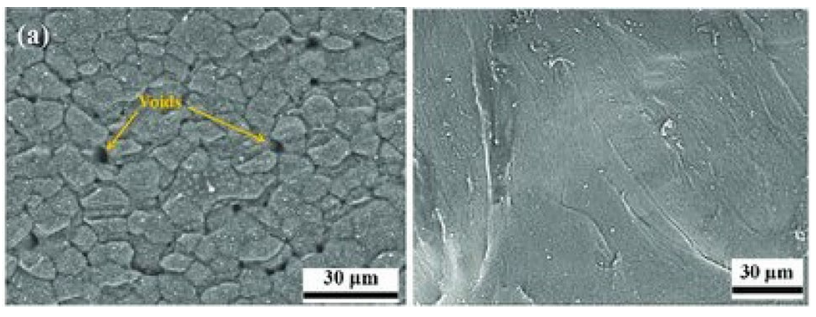

Fig. 3 SEM image of a solvent casted and $\mathbf{b}$ 3D printed PVDF film respectively

Roppola and the team members (2016) determined the effect of inducing the generation of silver ( $\mathrm{Ag}$ ) nanoparticles in the polymer matrix with polyethylene glycol diacrylate (PEDGA) as base materials. Upon exposure to the thermal treatment at the last stage of printing at $200{ }^{\circ} \mathrm{C}$, the resistivity increased, indicating that the nanocomposite treated at high temperature is not suitable for producing conductors [19].

In the effort to improve the dielectric property of a nanocomposite material, Yirong and the research team (2018) had conducted a research to explore the impact of adding barium titanate $\left(\mathrm{BaTiO}_{3}\right)$ and carbon nanotubes (CNTs) fillers into the poly(vinylidine) fluoride (PVDF) polymer [21]. By adding $\mathrm{BaTiO}_{3}$, the desirable energy storage ability of the nanocomposite is possible to be applied in field-effect transistor (FETs), capacitors and other embedded electronics. Dielectric materials are electrical insulators that can be polarized by an applied electrical field to store energy [140]. A nanocomposite filament was formed and printed using FDM 3-D printer namely Lulzbot Taz 5 [21]. The printed PVDF has a higher dielectric constant (16.6) than the solvent casted PVDF (15.0) due to the extrusion process of the filament and 3-D printing offers molecular alignment and hence it is able to remove micro-cracks and voids as shown in SEM images in Fig. 3. In addition, the incorporation of CNT filler has also reduced the impact and size of the microcracks and voids and has improved the dielectric strength of the nanocomposites [21]. It was also reported through extrusion-based 3-D printing technique, the nanoparticles were well-dispersed in the matrix [21].

Robot has its limitation in locomotion applications, especially wall-climbing and aqueous environment. A gecko-inspired robot was made by Jeong and the research team that can move on ceilings with different orientations which was produced using a selective laser sintering (SLS) type 3-D printer [141]. Besides, the team had incorporated fluorosilane-functionalized silica $\left(\mathrm{SiO}_{2}-\mathrm{F}\right)$ nanoparticles for water repellent characteristic and locomotion under the aqueous environment [141]. The team hopes to develop a practical robot which could be applied in air and water pollution monitoring with enhanced mobility and functionality. 


\subsubsection{Medical}

A 3-D detoxification device was created by 3-D printing hydrogels with functional polydiacetylene (PDA) nanoparticles by Gou and the team [20]. The objective of the study was to eliminate the risk of nanoparticles accumulation in human liver which may possess a secondary poisoning risk in liver failure patients through intravenous administration. The PDA can work effectively against pore-forming toxins (PFTs) since it is able to attract, capture and sense the toxins. PFTs are a toxin that can damage the cellular membrane due to pathologic infections by animal biting or bacterial infections. Result shows that after using this biomimetic detoxification device, the solutions totally lose its toxicity.

As scaffold is used in bones or tissues regeneration, it must be biodegradable and display no toxicity after decompose [142]. The ideal scaffold should also promote host cells regeneration, control the degradation rate of the scaffold and biocompatible with the host cells.

In research by Magdassi's research team (2016) to produce 3D printable hydrogels, water-dispersible nanoparticles were incorporated in 2,4,6-trimethylbenzoyl-diphenylphosphine oxide (TPO) to form hydrogels [143]. When the water-soluble photo-initiators with high absorbance in the UV range are absent, the formation of 3-D printed hydrogels are difficult. However, poly(ethylene glycol) diacrylate (PEGDA) hydrogels, the mechanical strength of the printed hydrogels which mechanical strength is six times greater than the normal hydrogel was printed successfully. This indicate that the printed hydrogels are strong enough to withstand their own weight and hence it is suitable for an implant and in situ purposes [143]. The fast polymerization of hydrogel with TPO nanoparticles is because TPO has a better solubility which aided a better dispersion and hence the free monomers are widely available to the newly formed free radicals.

A 3-D printed nanocomposite was produced in another study in orthopedic surgery and drug delivery system [144]. Since implants have to be strong to tolerate stress, nanoparticles are added into the polymer to improve the physical properties as in the mechanical strength of the implants. For this reason, carbon nanotubes (CNTs) and hydroxyapatite (HAp) are added into the poly(methyl-methacrylate) (PMMA) polymer.

The PMMA polymer is a biomaterial for joints or bones, CNTs are light weight, highly elastic, high heat stability, high strength, high electrics and high conductivity making it a good advantage over other nanoparticles. On the other hand, HAp is commonly used as a coating to improve cell diffusion into implants or act as a filler in bones [145]. The presence of CNTs content promotes a better dispersion of HAp nanoparticles based on the characterization using energy dispersive X-ray (EDX) analysis. Besides that, when the content of HAp was increased, a reduction in strength was observed as this leads to stress concentration and agglomeration of particles. 3-(4,5-dimethylthiazol-2-yl)2,5-diphenyl-2H-tetrazolium bromide (MTT) analysis result indicated that the presence of CNT with HAp improved the cell growth comparison to solely HAp and solely CNT in the nanocomposites as shown in Fig. 4. From Fig. 4, plain CNT led to a decrease in cell viability of PMMA matrix [144]. Both particles need to work synergically because CNT is toxic to cells meanwhile HAp particle is able to precipitate on the CNT particles and hence blocking its toxicity [144]. This nanocomposite serves as a good matrix for biomedical applications.

In a previous bone regeneration study by Rath and the research team [146], $\mathrm{SiO}_{2}$ nanoparticles were added into the sodium alginate to produce a scaffold [146]. Sodium alginate and gelatine, are natural polymer hydrogel, that is widely used in tissue engineering using 3-D bioprinting because their properties of biodegradability and biocompatibility [146]. However, hydrogel is not suitable to be used in tissue engineering due to the ineffectiveness to hold the structure on their own, lack of regeneration capability and swelling. By incorporating $\mathrm{SiO}_{2}$ nanoparticles, the free hydroxyl groups on its surface can interact with the sodium alginate-gelatine polymer and chemically crosslink with $\mathrm{CaCl}_{2}$ solution, which can address the above issues. From the study, the viscosity of the hydrogel ink increased to $2.5 \mathrm{wt} \%$ concentration when $\mathrm{SiO}_{2}$ nanoparticles was added into the hydrogel. In addition, this improved the viscosity and resulted in the printability of the scaffold. In addition, the compressive modulus (MPa) was significantly improved whereby degradation and swelling were inhibited. Furthermore, the cell proliferation and cell attachment of the printed model were enhanced due to micro-porosity. The 3-D printed virtual skull defect was successfully printed by as demonstrated in Fig. 5 using the formulated nanoparticle ink

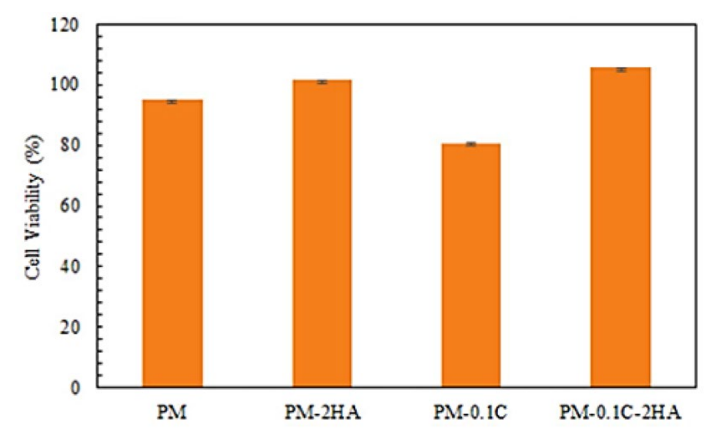

Fig. 4 Cell viability and microscope images from the MTT test. PM: PMMA. PM-2HA: PMMA with 2 wt $\%$ of HAp. PM-0.1C: PMMA with 0.1 wt $\%$ of CNT. PM-0.1C-2HA: PMMA with 0.1 wt\% CNT and $2 \mathrm{wt} \%$ HAp [144] 
Fig. 5 Process showing the 3-D printing of patient-specific virtual bone defect [146]

\section{Replacing patient specific 3D printed bone defect}
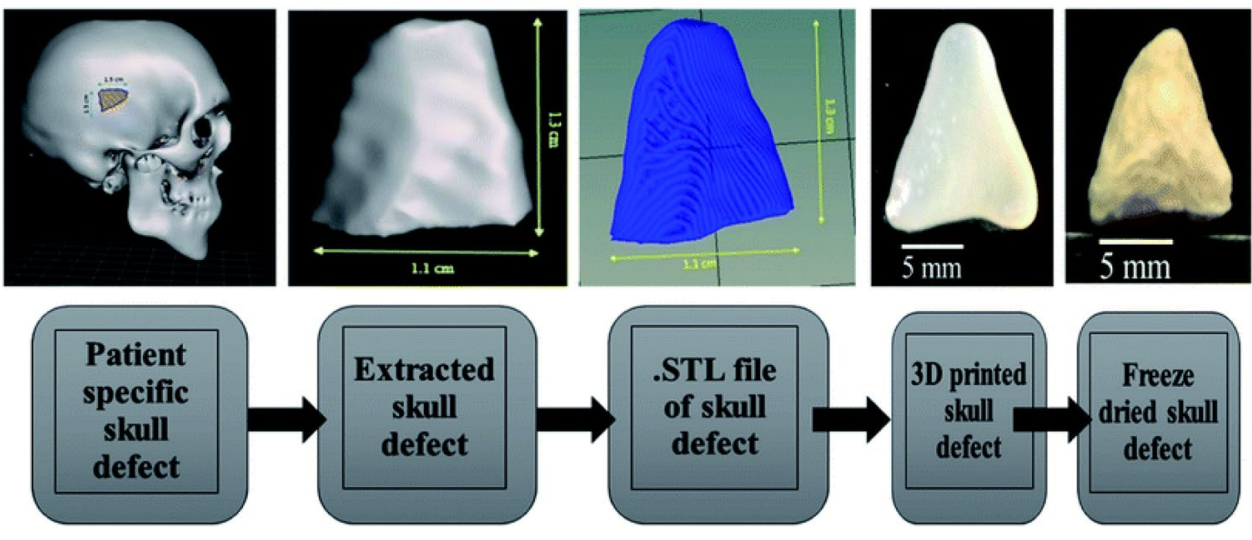

[146]. On the other hand, titanium dioxide nanoparticles $\left(\mathrm{TiO}_{2}\right)$ was suggested as a candidate in the bone regeneration field, mainly due to its enhanced bone-forming ability, high tensile strength $(\sim 110 \mathrm{GPa})$, resistant to corrosion, biocompatible and able to react with human tissue [147]. In another research, a bone tissue engineering scaffold was formed using single-walled nanotubes (SWNT) as the nanoparticle and poly(propylene fumarate) (PPF) as the polymer [148]. It was realised that SWNT was able to strengthen the weak PPF material as well as producing scaffold that is light-weight and strong. This scaffold was also shown to be highly conductive. This property is beneficial for some applications since some cell functions are stimulated via electric current, thus promoting bone-forming ability [148]. Besides designing scaffolds that are biocompatible, light-weight, strong, non-toxic, Jiji and the team had produced a scaffold made of silver (Ag) nanoparticles and bacterial cellulose-polydopamine (BCPDA) polymer that exhibit antibacterial effects. The scaffold was evaluated against gram-positive (Staphylococcus aureus) and gram-negative bacteria (Escherichia coli, Pseudomonas aeruginosa and Klebsiella pneumoniae).
Fig. 6 Factors to be concerned when designing and building bone regeneration scaffold

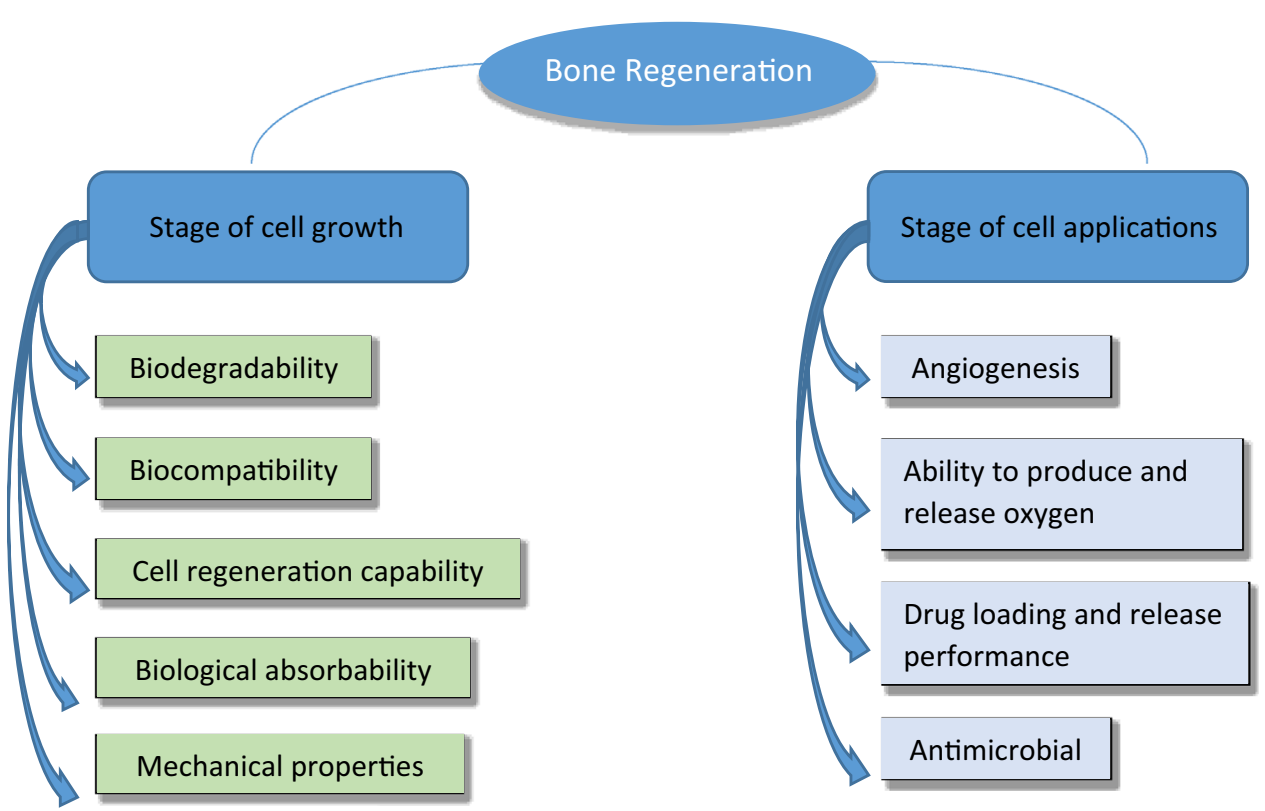


There are a few parameters that is needed to take into consideration when producing bone regeneration scaffold as in Fig. 6 such as biocompatibility, biological absorbability and mechanical properties are important to support cell growth while maintaining its mechanical strength. Other factors such as angiogenesis, the ability to produce and release oxygen, antimicrobial property, drug loading and release performance are some other important aspects that need to be taken into consideration when designing an applicable scaffold [49, 149].

\subsubsection{Food industry}

Prevention of microbial growth at the food manufacturing plant is especially important to prevent spoilage of food. Microbial infection is a major concern because microbes may deposit onto the surface of a polymer belt that is used to transfer food from one station to another, hence causing microbial contamination at the production site. One of the solutions is to utilise polymer belt with antimicrobial function in the production line. Nanocomposites give an advantage to food industry by disinfectant equipment or spare parts such as the polymer belt that is used to transfer and transport the materials. Silver nanoparticles (Ag) were incorporated into the polylactic acid (PLA) polymer to test

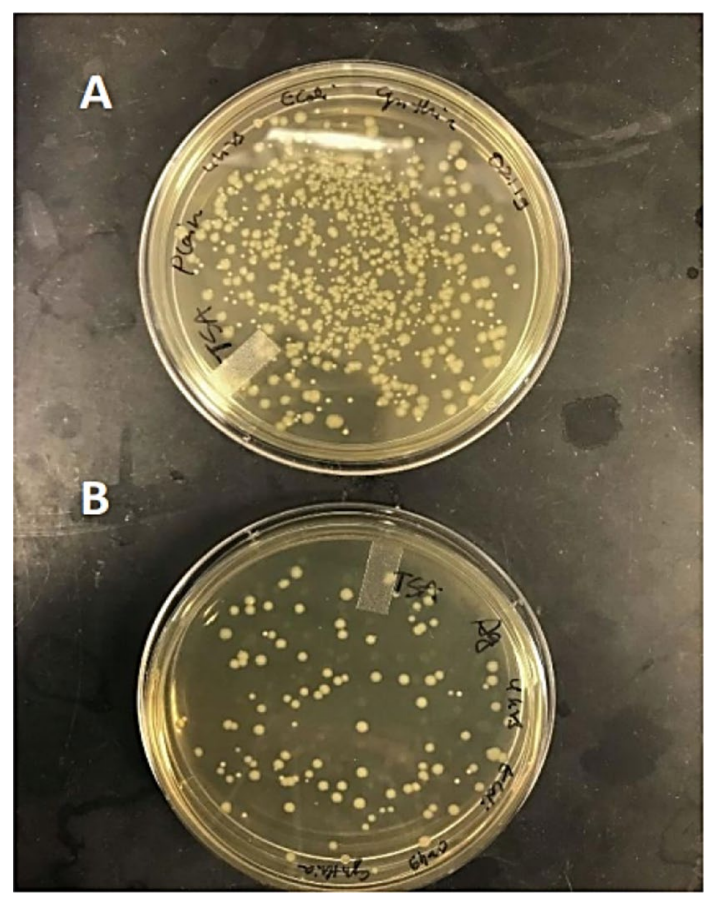

Fig. 7 Comparative antimicrobial result. A Plated on Plain PLA disc for $4 \mathrm{~h}$. B Plated on $2.5 \mathrm{wt} \%$ PLA disc for $24 \mathrm{~h} \mathrm{[150]}$ for its antimicrobial ability [150]. With the idea of incorporating nanoparticles into the polymer belt, it saved the cost and time that spent on a large amount of disinfectant used and labour sue to its antimicrobial ability [150]. The printed polymer belt contained of Ag performed antimicrobial activities which was obviously lower if compared to polymer belt without Ag as shown in Fig. 7 in the antibacterial test by colony count.

Antimicrobial food packaging is also an interesting aspect to study on, since the addition of additives in food packaging can contribute to expanding the shelf-life of a particular food product. Among all the antimicrobial additives, silver $(\mathrm{Ag})$ and titanium dioxide $\left(\mathrm{TiO}_{2}\right)$ nanoparticles are the most commonly studies ones since these nanoparticles exhibit strong antibacterial performance against bacteria, fungi and virus $[76,151]$, which are the most common pathogens in food. For instance, the shelf-life of chicken breast fillet was extended when silver-low density polyethylene (Ag/LDPE) nanocomposite was used as an antibacterial packaging [152]. Silver-polyethylene (Ag/PE) nanocomposite displayed excellent antibacterial activity against meat-spoilage bacteria such as Leuconostoc gelidum subsp. Gasicomitatum and Lactococcus piscium [153]. In the application of rice packaging, silver-titanium dioxide $\left(\mathrm{Ag} / \mathrm{TiO}_{2}\right)$ was incorporated into the PE polymer which displays excellent antimicrobial activity against Aspergillus flavus [154].

\subsubsection{Wastewater treatment}

In developing countries, where the human population increases, tourist hotspot and hotspot for manufacturing goods, water pollution is often not handled well and discharged into the water mainstream such as the sea and river. Polluted water affects the quality of life of human and aqueous living organisms. It also causes infections in human such as cholera that is caused by bacterial contamination from the water source. Even though various method such as chlorination, chemical coagulation and chemical absorption had been adopted to remove these bacterial contaminants and chemicals, some chemicals are difficult to remove through these ordinary methods [155].

In the previous study, anatase $\mathrm{TiO}_{2}$ nanoparticles with the size $<25 \mathrm{~nm}$ is used since it is a great photocatalyst to degrade pollutants [156]. Anatase phase $\mathrm{TiO}_{2}$ nanoparticles were used rather than rutile because supported anatase can produce more hydroxyl radicals compared to rutile phase on the activated carbon [156]. Polyethylene (LDPE) was chosen to be the host material to hold the nanosized $\mathrm{TiO}_{2}$ as it has a lower density than water so that it can float on the surface of the water. The idea to use a floating material 
gives accessibility for the $\mathrm{TiO}_{2}$ to be exposed to ultra-violet (UV) radiation which is contributed from the solar radiation. Furthermore, most of the pollutants floats on the surface of the water which is corresponding to the floating material. With the presence of $\mathrm{TiO}_{2}$ anatase as photocatalyst, the rate of degradation of the pollutant increased to $8 \%$ in two hours due to photocatalysis of $\mathrm{TiO}_{2}$ under $\mathrm{UV}$ radiation, therefore, increasing the formation of hydroxyl radicals and hence the removal of methylene blue (MB). This is proven with the production of cellulose membrane incorporated with $\mathrm{TiO}_{2}$ for photodegradation of organic dye $[56,57]$. $\mathrm{TiO}_{2}$ as catalyst in embedded form is more sustainable because it is reusable and recyclable. This is proven with the production of cellulose membrane incorporated with $\mathrm{TiO}_{2}$ for photodegradation of organic dye [56, 57].

It is well-known that silver possess an excellent antimicrobial property especially targeting drug-resistant gramnegative bacteria [157] whereas titania possess outstanding photocatalytic performance [156]. Titania nanoparticles was embedded into the silver matrix to produce 3-D printed micro-device that is applicable to environmental antimicrobial activities [73]. The antimicrobial activity was tested against Staphylococcus aureus by colony-forming unit (CFU) and the photocatalytic performance was tested against a model dye Rhodamine $\mathrm{B}(\mathrm{RhB})$ under ultraviolet (UV) irradiation using the printed micro-device. The viability of bacteria decreased from 62 to $22 \%$ compared to the uncoated specimen. Meanwhile, the micro-device containing nanoparticles showed an improvement of dye degradation for 6 times higher compared to the one measured without device [73]. This proposed micro-device is suitable in applications that requires both antimicrobial and removal of contaminants.

3-D printed nanocomposites play an important role in various applications. Nanocomposites which comprised of two or more types of materials can produce end product with unique characteristics and added-value functionality. Table 6 summarizes the advantages of nanocomposites that used in various applications.

\section{The drawbacks of nanocomposite in 3-D printing}

The current selection of materials set certain boundaries for the additive manufacturing. There might be more functionalities needed to explore since new applications are increasing with the developing technologies especially to produce 3-D printed composites. Meanwhile, the production of 3-D printed composites often suffers from problems such as inhomogeneity of solution or mixture, difficulties in controlling viscosity, necking after the printing and etc. Ultrasonication, mechanical stirring, precipitation and meltmixing are methods used to form composite material [168]. Shrestha [150] reported the drawback of the research is that the Ag nanoparticles will be stuck at the 3-D printer

Table 6 Summary of 3D-printed nanocomposites used in various research on 3-D printing technology

\begin{tabular}{|c|c|c|c|c|c|}
\hline Polymer & Nanoparticle & Field of application & Method of printing & Advantages & References \\
\hline PVDF & $\mathrm{BaTiO}_{3}, \mathrm{CNT}$ & Energy storage & FDM & $\begin{array}{l}\text { Improves dielectric property of the nano- } \\
\text { composite }\end{array}$ & {$[21,158]$} \\
\hline Nylon 12 (PA 12) & $\mathrm{SiO}_{2}-\mathrm{F}$ & Robotic, water treatment & SLS & $\begin{array}{l}\text { Provide water repellent characteristic } \\
\text { Enhances locomotion under the aqueous } \\
\text { environment }\end{array}$ & {$[141,159]$} \\
\hline PEGDA & PDA & Detoxification device & DOPsL & $\begin{array}{l}\text { Able to capture toxins using PDA nanopar- } \\
\text { ticles } \\
\text { No accumulation of nanoparticles in human } \\
\text { body }\end{array}$ & {$[20,160]$} \\
\hline Hydrogels & ТPO & Biomedical & SLA & $\begin{array}{l}\text { Strong weight scaffold that is suitable for } \\
\text { implants }\end{array}$ & {$[143,161]$} \\
\hline PMMA & CNTs, HAp & Biomedical & FDM & $\begin{array}{l}\text { High mechanical strength } \\
\text { Promotes cell growth }\end{array}$ & {$[144,162,163]$} \\
\hline Hydrogel & $\mathrm{SiO}_{2}$ & Biomedical & N/A & $\begin{array}{l}\text { Enhances bone forming ability } \\
\text { High tensile strength } \\
\text { Resistant to corrosion } \\
\text { Biocompatible to human tissues }\end{array}$ & {$[146,164]$} \\
\hline PLA & $\mathrm{Ag}$ & Food & N/A & $\begin{array}{l}\text { Incorporation of nanoparticles provide } \\
\text { antimicrobial to the polymer belt }\end{array}$ & {$[150,165]$} \\
\hline LDPE & $\mathrm{TiO}_{2}$ & Water treatment & FDM & $\begin{array}{l}\text { Able to float on water for sunlight exposure } \\
\text { to the nanoparticles }\end{array}$ & {$[166,167]$} \\
\hline $\mathrm{Ag}$ & $\mathrm{TiO}_{2}$ & Water treatment & SLA & $\begin{array}{l}\text { Dual functionality of acting as photocatalyst } \\
\text { and antimicrobial }\end{array}$ & {$[73,167]$} \\
\hline
\end{tabular}


nozzle once the amount is $5 \mathrm{wt} \%$ or more. Theoretically, the higher the nanoparticles, the better the performance of the particular functionality. Nevertheless, the percentage of nanoparticles is required to keep at the optimum level to minimize the problem of blocking at the nozzle. The concentration of nanoparticles incorporated must be adjusted to avoid agglomeration formation during the printing process meanwhile the composite able to exhibit its enhanced properties [169]. On top of that, not all the printing techniques are ideal as some of the resolution of printing techniques are not high enough to meet the minimum requirement of the printed objects. There are 3-D printers that are printing at low speed and clogging issues may arise at the nozzle. The nozzle may also experience wear and tear issues after repeating process of printing for few times thus affecting the resolution of the printed object. The best concentration of additive is desired to figure out which compatible with the speed and temperature of the 3-D printers preceding the printing process.

Despite of the limitations mentioned above, researchers have been optimizing the homogeneity of the nanocomposite printing ink by various method. In the report by Chidambaram and the team members, it was suggested that solution blending is the most popular method to blend different compounds together. This method is able to control the homogeneity of the nanocomposite [118]. In the report, 25 wt $\%$ of the aluminium oxide $\left(\mathrm{Al}_{2} \mathrm{O}_{3}\right)$ nanoparticles were successfully incorporated into the cellulose acetate (CA) polymer. This homogeneity of the incorporated nanoparticles was confirmed through a scanning electron microscope (SEM) and atomic force microscopy (AFM) analysis. The incorporation of $\mathrm{Al}_{2} \mathrm{O}_{3}$ into the polymer matrix enhances the dielectric properties three times greater than using the CA film alone, along with increased thermal stability [118]. In another research to produce light-weight material for metal-based industry, $30 \mathrm{vol} . \%$ of titanium diboride $\left(\mathrm{TiB}_{2}\right)$ and titanium carbide (TiC) nanoparticles was successfully incorporated into the aluminium $(\mathrm{Al})$ and magnesium $(\mathrm{Mg})$ matrix through a similar process which is mechanical mixing for a few hours [119]. Besides solution blending, it was also reported in a few researches that solid-state shear milling technique can also enhance the dispersion of nanoparticles in the polymer matrix [170-172]. It is a new technique that involves grinding of additive and polymer below the melting point of the polymer to maintain the solid state of the polymer. High shear will cause fragmentation of the polymer thus promoting uniform dispersion of nanoparticles in the polymer. This method does not involve the use of expensive or dangerous solvents, and also does not change the properties of the polymer since the process is thermally controlled beyond its melting point [172].
There is a study reported that the nozzle abraded on the surface and inside the body of the objects during printing as the nozzle attached to the printing object. The degradation of the nozzle has affected the resolution which may also affect the functionality and the appearance of the object [114]. Since composite requires mixing of different materials, properties such as viscosity will affect the printability of the final object. Some printing methods require higher viscous of printing ink such as the extrusion-based printing. If low viscous printing ink is used in extrusion-based printer, the product will lack in shape [168]. However, high viscous printing ink is also another issue since it may cause clogging at the nozzle. It should also be noted that higher extrusion temperature is required if nanoparticles were incorporated into the polymer since the increment of melt viscosity requires higher extrusion temperature. These factors may be the reasons for some of the manufacturers are still adopting traditional manufacturing. The experimental test on viscosity of printing ink is required prior to the exact printing process. This experiment may be conducted with the change of other factors such as speed of printing, temperature and concentration of the printing mixture/ solution.

Regardless of the ready 3-D printers, the discovery from the engineers are more appreciable in terms of invention of new improved 3-D printer models. The design of the printers not only depends on the ordinary factors but also types of additives to be added such as suitable irradiation, targeted end product as composite or additive embedded materials, temperature to achieve in-situ chemical reaction if the end product is composite, possible of treatment to be done in the 3-D printer just after the printing process as listed in Fig. 8.

\section{Conclusion}

In this review, the advancement of 3-D printing in various fields has been identified. By looking at the unlimited and high potential application of 3-D printing, continuous researches should be permitted and explored especially 3-D printed nanocomposites. The incorporation of nanoparticles has proven to create and build more functional products. The incorporation of nanoparticles has many added-values such as acting as a filler to increase the mechanical properties, improve the dielectric properties and even biological properties of the printed products. This review also provides the information to the manufacturers and researchers to encourage the enhancement of 3-D printing in terms of sustainability and recyclability of the system. Last but not least, study should be carried on to overcome the drawbacks of 
Fig. 8 Factors to be concerned in designing a 3-D printer

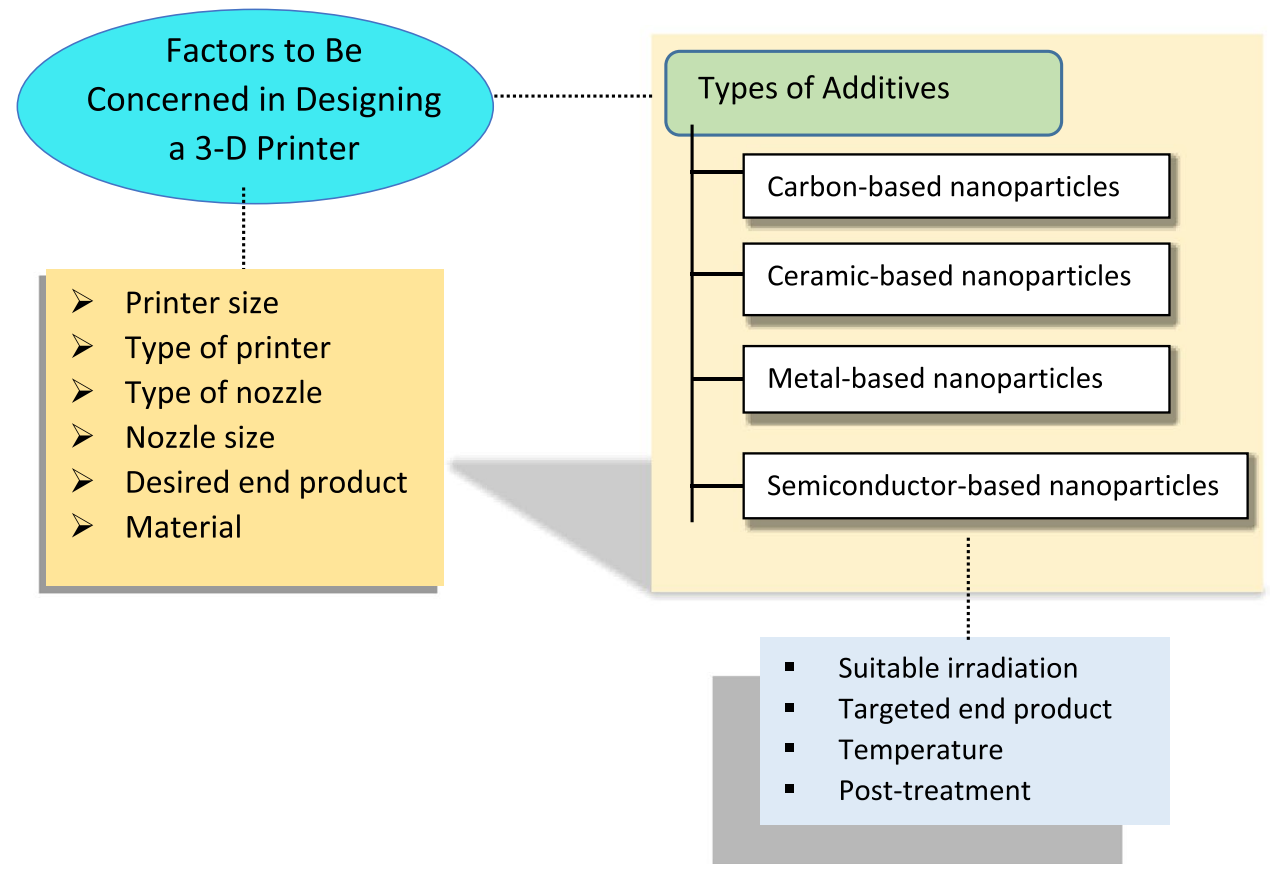

3-D printed nanocomposites as discussed. It is believed that the innovation and invention by engineers to design specific 3-D printer for nanocomposites could reduce or avoid the problems crossed the barriers of limitation nowadays. 3-D printing is an important aspect to explore because it will revolutionize the future of development and could generate much income in various sectors. However, current limitations exist such as the lack of operation expertise and the cost of producing 3-D printed goods. We are aiming to have more amazing implementations of 3-D technology in the upcoming years.

\section{References}

1. Flynt J. A detailed history of 3D printing. 3D Insider. (n.d) https://3dinsider.com/3d-printing-history/. Accessed 15 Feb 2020

2. Kohut A. Making it work: $3 \mathrm{D}$ printing and engineering. Ultimaker (2019) https://ultimaker.com/learn/making-it-work-3dprinting-and-engineering. Accessed 2 Apr 2020

3. Sculpteo (2018) The state of 3D printing https://www.sculpteo. com/media/ebook/State_of_3DP_2018.pdf. Accessed 3 Apr 2020

4. Canton C (2014) Industrial applications of 3D printing, Think3D. https://www.think3d.in/industrial-applications-of-3d-printing/. Accessed 3 Apr 2020

5. Gebhardt A, Kessler J, Thurn L (2018) Applications of additive manufacturing. 3D Printing, pp 101-136.

6. Vivero-Lopez M, Xu X, Muras A, Otero A, Concheiro A, Gaisford S, Goyanes A (2021) Anti-biofilm multi drug-loaded 3D printed hearing aids. Mater Sci Eng C 119:111606

7. World Heath Organization (2020) Deafness and hearing loss. https://www.who.int/news-room/fact-sheets/detail/deafness-andhearing-loss. Accessed 2 Apr 2020.
8. Mashambanhaka F (2019) Medical 3D printing: The best healthcare applications, All3DP, https://all3dp.com/2/3d-printing-inmedicine-the-best-applications/. Accessed 2 Apr 2020

9. Aimar A, Palermo A, Innocenti B (2019) The role of 3D printing in medical applications: a state of the art. J Healthc Eng 10:1-10

10. Gonzalez C (2019) 3D printing new skin by a patient's beside. Machine Design. https://www.machinedesign.com/3d-printingcad/article/21837617/3d-printing-new-skin-by-a-patients-bedsi de. Accessed 15 Feb 2020

11. Hakimi N, Cheng R, Leng L, Sotoudehfar M, Ba PQ, Bakhtyar $\mathrm{N}$, Gunther A (2018) Handheld skin printer: in situ formation of planar biomaterials and tissues. Lab Chip 18(10):1440-1451

12. Tareq MS, Rahman T, Hossain M, Dorrington P (2021) Additive manufacturing and the COVID-19 challenges: an in-depth study. J Manuf Syst

13. Bassam NA, Hussain SA, Qaraghuli AA, Khan J, Sumesh EP, Lavanya V (2021) IoT based wearable device to monitor the signs of quarantined remote patients of COVID-19. Inform Med Unlocked 24:100588

14. Goswami M, Yadav AK, Chauhan V, Singh N, Kumar S, Das A, Yadav V, Mandal A, Tiwari JK, Siddiqui H, Ashiq M, Sathish N, Kumar S, Biswas D, Srivastava AK (2021) Facile development of graphene-based air ilters mounted on 3D printed mask for COVID-19. J Sci Adv Mater Devices 6:407-414

15. Belhouideg S (2020) Impact of 3D printed medical equipment on the management of the Covid19 pandemic. Wiley Public Health Emergency Collection

16. Kumar R, Kumar R (2020) 3D printing of food materials: A state of art review and future applications. Mater Today Proc 33:1463-1467

17. Pant A, Lee AY, Karyappa R, Lee C, An J, Hashimoto M, Tan UX, Wong G, Chua CK, Zhang Y (2020) 3D food printing of fresh vegetables using food hydrocolloids for dysphagic patients. Food Hydrocolloids 114:106546

18. Ng DS, Paul SC, Anggraini V, Kong SY, Qureshi TS, Rodriguez CR, Liu QF, Savija B (2020) Influence of $\mathrm{SiO}_{2}, \mathrm{TiO}_{2}$ and $\mathrm{Fe}_{2} \mathrm{O}_{3}$ nanoparticles on the properties of fly ash blended cement mortars. Constr Build Mater 258:119627 
19. Fantino E, Chiappone A, Calignano F, Fontana M, Pirri F, Roppolo I (2016) In situ thermal generation of silver nanoparticles in 3D printed polymeric structures. Materials 9(7):589

20. Gou M, Qu X, Zhu W, Xiang M, Yang J, Zhang K, Wei Y, Chen S (2014) Bio-inspired detoxification using 3D-printed hydrogel nanocomposites. Nat Commun 5:3774

21. Kim HJ, Johnson J, Chavez L, Garcia C, Tseng B, Lin YR (2018) Enhances dielectric properties of three phase dielectric MWC NTs/BaTiO3/PVDF nanocomposites for energy storage using fused deposition modelling 3D printing. Ceram Int 44(8)

22. Wang X, Jiang M, Zhou Z, Gou J, Hui D (2017) 3D printing of polymer matrix composites: a review and prospective. Compos Part B 110:442-458

23. Jasveer S, Jianbin X (2018) Comparison of different types of 3D printing technologies. Int J Sci Res Publ 8(4):2250-3153

24. Borrello J, Nasser P, Iatridis J, Costa KD (2018) 3D printing a mechanically-tunable acrylate resin on a commercial DLP-SLA printer. Addit Manuf 23:374-380

25. Stansbury JW, Idacavage MJ (2016) 3D printing with polymers: challenges among expanding options and opportunities. Dent Mater 32:54-64

26. Syed AMT, Elias PK, Amit B, Susmita B, Lisa O, Charitidis C (2017) Additive manufacturing: scientific and technological challenges, market uptake and opportunities. Mater Today $1: 1-16$

27. Scharff RBN, Doubrovski EL, Poelman WA, Jonker PP, Wang CCL, Geraedts JMP (2017) Towards behaviour design of a 3D-printed soft robotic hand. Biosyst Biorobot 17:23-29

28. Ventola CL (2014) Medical application for 3D printing: current and projected uses. Med Dev 39(10):1-8

29. Tiwari SK, Pande S, Agrawal S, Bobade SM (2015) Selection of selective laser sintering materials for different applications. Rapid Prototyp J 21(6):630-648

30. Fan Z, Feng H (2018) Study on selective laser melting and heat treatment of Ti-6Al-4V alloy. Results Phys 10:660-664

31. Shakor P, Nejadi S, Paul G, Malek S (2019) Review of emerging additive manufacturing technologies in $3 \mathrm{~d}$ printing of cementitious materials in the construction industry. Front Built Environ 4:85

32. Vikayavenkataraman S, Jerry YHF, Wen FL (2017) 3D printing and 3D bioprinting in pediatrics. Bioengineering 4(63):1-11

33. Xian LZ, Yen TC, Ray MR, Mattia D, Metcalfe IS, Patterson DA (2016) Perspective on 3D printing of separation membranes and comparison to related unconventional fabrication techniques. J Membr Sci 523(1):596-613

34. Ze-Xian L, Yen TC, Ray MR, Mattia D, Metcalfe IS, Patterson DA (2016) Perspective on 3D printing of separation membranes and comparison to related unconventional fabrication techniques. J Membr Sci 523(1):596-613

35. Silbernagel C (2018) Additive manufacturing 101-4: what is material jetting? Canada Makers. http://canadamakes.ca/whatis-material-jetting/. Accessed 2019

36. Flynt. (2018) What is SLA 3d printing?. 3D Insider. https:// 3dinsider.com/what-is-sla/. Accessed 1 Apr 2020

37. Obel MV (2019) 3D printing materials guide. All3DP. https:// all3dp.com/1/3d-printing-materials-guide-3d-printer-material/. Accessed 7 Feb 2020

38. Pick 3D Printer (n.d) A complete guide to 3D printing materials. https://pick3dprinter.com/3d-printing-materials/\#3d-print ing-material-metals. Accessed 24 June 2020

39. Kamran M, Saxena A (2016) A comprehensive study on 3D printing technology. MIT Int J Mech Eng 6(2):63-69

40. Greguric L (2018) PVA filament-the basics \& best brands. All3DP. https://all3dp.com/2/pva-filament-explained-andcompared/. Accessed 23 June 2020
41. Flynt J (2020) Flexible TPE filament: properties, how to use, and best brands. 3D Insider. https://3dinsider.com/flexible-tpefilament/. Accessed 15 June 2020

42. Chen A (2020) Top 10 materials used for industrial 3D printing. C-Mac Industries https://www.cmac.com.au/blog/top-10materials-used-industrial-3d-printing. Accessed 12 June 2020

43. Carlota V (2019) All you need to know about PETG for 3D printing. 3D Natives. https://www.3dnatives.com/en/petg-3dprinting-guide-181220194/. Accessed 17 June 2020

44. Kondo H (2019) 5 Easy tips for 3D printing with PETG \& print settings. All3DP. https://all3dp.com/2/3d-printing-with-petghow-to-succeed/. Accessed 17 June 2020

45. Flynt J (2020) PETT filament: Properties, how to use, and best brands. 3D Insider. https://3dinsider.com/pett-filament/. Accessed 19 June 2020

46. gCreate Team (2019) A brief but informative breakdown of PET, PETG, and PETT. gCreate. https://www.gcreate.com/ post/what-is-pet-petg-pett. Accessed 19 June 2020

47. Carolo L (2020) HIPS filament: the basics \& best brands. All3DP. https://all3dp.com/2/hips-filament-the-basics-bestbrands/. Accessed 24 June 2020

48. Flynt J (2018) Dissolvable HIPS filament properties and best brands. 3D Insiderhttps://3dinsider.com/hips-filament/. Accessed 24 June 2020

49. Sinha SK (2020) Additive manufacturing (AM) of medical devices and scaffolds for tissue engineering based on 3D and $4 \mathrm{D}$ printing. In: 3D and $4 \mathrm{D}$ printing of polymer nanocomposite materials, pp 119-160

50. Heo S, Oh G, Jung W (2020) 3D printed marine biomaterials composites for bone tissue engineering. Encycl Mar Biotechnol 2:1299-1314

51. Li X, Cui R, Sun L, Aifantis KE, Fan Y, Feng Q, Cui F, Watari F (2014) 3D-Printed biopolymers for tissue engineering application. Polym Scaffolds Tissue Eng 2014 24:1-13

52. Zafar MJ, Zhu D, Zhang Z (2019) 3D printing of bioceramics for bone tissue engineering. Materials 12(20):3361

53. Wen Y, Xun S, Haoye M, Baichuan S, Peng C, Xuejian L, Shibi L (2017) 3D printed porous ceramic scaffolds for bone tissue engineering: a review. Biomater Sci 5(9):1690-1698

54. Yeo M, Jung WK, Kim G (2012) Fabrication, characterisation and biological activity of phlorotannin-conjugated PCL/ $\beta$-TCP composite scaffolds for bone tissue regeneration. J Mater Chem 22(8):3568-3577

55. Wihesinghe WAJP, Ko SC, Jeon YJ (2011) Effect of phlorotannins isolated from Ecklonia cava on angiotensin I-converting enzyme (ACE) inhibitory activity. Nutr Res Pract 5(2):93-100

56. Evyan Y, Salleh K, Chong MY, Chia CH, Zakaria S (2021) Effect of dimensionality of nanosized $\mathrm{TiO}_{2}$ embedded in regenerated cellulose beads as a portable catalyst for reusable decomposition system. Polym Adv Technol MI-2020-006 32(9):3549-3562

57. Evyan Y, Zakaria S, Chia C (2017) Bifunctional regenerated cellulose membrane containing $\mathrm{TiO}_{2}$ nanoparticles for absorption and photocatalytic decomposition. Sains Malaysianna 46(4):637-644

58. Gaget L (2019) Materials used in 3D printing. Sculpteo. https:// www.sculpteo.com/blog/2019/08/28/materials-used-in-3dprinting/. Accessed 7 Feb 2020

59. Varotsis $A B$ (n.d) Introduction to 3D metal printing. 3dhubs. https://www.3dhubs.com/knowledge-base/introduction-metal3d-printing/. Accessed 12 June 2020

60. Process Industry Forum (n.d) Advantages and disadvantages of metals commonly used in manufacturing.: https://www.proce ssindustryforum.com/article/advantages-disadvantages-metals-commonly-used-manufacturing\#: :text=It $\% 20$ is $\% 20$ hard $\%$ 
2C\%20ductile\%20and,of\%20dermatitis\%20among\%20sensitiz ed\%20individuals. Accessed 24 June 2020

61. 3D Printing. 3D Printing Materials. https://3dprinting.com/ materials/. Accessed 7 Feb

62. Monkova K, Zetkova I, Kucerova L, Zetek M, Monka P, Dana M (2018) Study of 3D printing direction and effects of heat treatment on mechanical properties of MS1 maraging steel. Arch Appl Mech 89(1):791-804

63. AZoM (2012) Tungsten-mechanical properties and material applications. AZO Materials. https://www.azom.com/article. aspx?ArticleID=7641. Accessed 12 June 2020

64. Beamler (2020) 3D printing with tungsten and tungsten carbide. Beamler Additive Manufacturing. https://www.beaml er.com/3d-printing-with-tungsten-and-tungsten-carbide/. Accessed 25 June 2020

65. 3dfabprint (n.d) Rewrite: how 3d printing changing the history of nickel alloys. Available: https://3dfabprint.com/rewri te-3d-printing-changing-history-nickel-alloys/. Accessed 24 June 2020

66. Martin JH, Yahata BD, Hundley JM, Mayer JA, Schaedler TA, Pollock TM (2017) 3D printing of high strength aluminium alloys. Nature 549:365-369

67. Botelho EC, Silva RA, Pardini LC, Rezende MC (2006) A review on the development and properties of continuous fiber/epoxy/ aluminium hybrid composites for aircraft structures. Mater Res 9:247-256

68. Altiparmak SC, Yardley VA, Shi Z, Lin J (2021) Challenges in additive manufacturing of high-strength aluminium alloys and current developments in hybrid additive manufacturing. Int $\mathbf{J}$ Lightweight Mater Manuf 4(2):246-261

69. Chen Z, Li Z, Li J, Liu C, Lao C, Fu Y, Li Y, Wang P, He Y (2019) 3D printing of ceramics. J Eur Ceram Soc 39(4):661-687

70. Yen HC (2014) Experimental studying on development of slurrylayer casting system for additive manufacturing of ceramics. Int J Adv Manuf Technol 77:915-925

71. Friedel T, Travitzky N, Niebling F, Scheffler M, Greil P (2005) Fabrication of polymer derived ceramic parts by selective laser curing. J Eur Ceram Soc 25(23):193-197

72. Cherdo L (2021) Ceramic 3D printing 2021: guide and ceramic 3D printer selection. Aniwwa. https://www.aniwaa.com/buyersguide/3d-printers/ceramic-3d-printer/. Accessed 24 June 2020.

73. Bernasconi R, Carrara E, Hoop M, Mushtaq F, Chen X, Nelson BJ, Pane S, Credi C, Levi M, Magagnin L (2019) Magnetically navigable $3 \mathrm{D}$ printed multifunctional microdevices for environmental applications. Addit Manuf 28:127-135

74. Anajafi Z, Naseri M, Neri G (2019) Acetone sensing behaviour of $\mathrm{p}-\mathrm{SmFeO}_{3} / \mathrm{n}-\mathrm{ZnO}$ nanocomposite synthesized by thermal treatment method. Sens Actuators B: Chem 304:127252

75. Sasmal A, Sen S, Devi PS (2020) Synthesis and characterization of $\mathrm{SmFeO}_{3}$ and its effect on the electrical and energy storage properties of PVDF. Mater Res Bull 2020(130):110941

76. Krepker M, Shemesh R, Poleg YD, Kashi Y, Vaxman A, Segal E (2017) Active food packaging films with synergistic antimicrobial activity. Food Control 76:117-126

77. Khan I, Saeed K, Khan I (2017) Nanoparticles: properties, applications and toxicities. Arab J Chem 12(7):908-931

78. Lee K, Hwang Y, Cheong S, Choi Y, Kwon L, Lee J, Kim SH (2009) Understanding the role of nanoparticles in nano-oil lubrication. Tribol Lett 35:127-131

79. Ahmadpour N, Sayadi MH, Sobhani S, Hajiani M (2020) Photocatalytic degradation of model pharmaceutical pollutant by novel magnetic $\mathrm{TiO}_{2} @ \mathrm{ZnFe}_{2} \mathrm{O}_{4} / \mathrm{Pd}$ nanocomposite with enhanced photocatalytic activity and stability under solar light irradiation. J Environ Manag 271:110964
80. Zhang Y, Purssell C, Mao K, Leigh S (2019) A physical investigation of wear and thermal characteristics of 3D printed nylon spur gears. Tribol Int 141:105953

81. Zachary TA, Ghasemi NMN (2020) Additive manufacturing/3D structure-related multifunctional properties. In: Structure and properties of additive manufactured polymer components, pp 87-113

82. Dickson AN, Barry JN, McDonnell KA, Dowling DP (2017) Fabrication of continuous carbon, glass and Kevlar fibre reinforced polymer composites using additive manufacturing. Addit Manuf $16: 146-152$

83. Justo J, Távara L, García-Guzmán L, París F (2018) Characterization of 3D printed long fibre reinforced composites. Compos Struct 185:537-548

84. Block LG, Longana HMY, Woods BKS (2018) An investigation into 3D printing of fibre reinforced thermoplastic composites. Addit Manuf 22:176-186

85. Lee J (2019) Carbon nanotube-based membranes for water purification, pp 309-331

86. Walker K (2015) Working with carbon nanoparticles. Azonano. https://www.azonano.com/article.aspx?ArticleID=4149. Accessed 12 July 2021.

87. Zhai Y, Zhu Z, Dong S (2015) Carbon-based nanostructures for advanced catalysis. ChemCatChem 7(18):2806-2815

88. Jahangir MN, Billah KMM, Lin Y, Roberson DA, Wicker RB, Espalin D (2019) Reinforrcement of material extrusion 3D printed polycarbonate using continuous carbon fiber. Addit Manuf 28:354-364

89. Singh B, Kumar R, Singh Chohan J (2020) Polymer matrix composites in 3D printing: a state of art review. Mater Today Proc 33:1562-1567

90. Yu JG, Zhao XH, Yang H, Chen XH, Yang Q, Yu LY, Jiang JH, Chen XQ (2014) Aqueous adsorption and removal of organic contaminants by carbon nanotubes. Sci Total Environ 482-483:241-251

91. Yanez H, Wang JEZ, Lege S, Obst M, Roehler S, Burkhardt CJ, Zwiener C (2017) Application and characterization of electroactive membranes based on carbon nanotubes and zerovalent iron nanoparticles. Water Res 108:78-85

92. Dong H, Zeng G, Tang L, Fan C, Zhang C, He X, He Y (2015) An overview on limitations of $\mathrm{TiO}_{2}$-based particles for photocatalytic degradation of organic pollutants and the corresponding countermeasures. Water Res 79:128-146

93. Lu W, Li Q, Chou TW (2018) 1.2 Carbon nanotube based fibers. Compr Compos Mater II:13-40

94. Dresselhaus MS, Dresselhaus G, Eklund PC, Rao AM (2001) Carbon nanotubes. The physics of fullerene-based and fullerenerelated materials, pp 331-379

95. Thomas SC, Sharma H, Mishra PK, Talegoankar S (2015) Ceramic nanoparticles: fabrication methods and applications in drug delivery. Curr Pharm Des 21(42):6165-6188

96. Vega AIM, Quintero TG, Anita REN, Torres LSA, Castano V (2012) Polymeric and ceramic nanoparticles in biomedical applications. Nanomater Synth Appl Toxic 2012 10(2)

97. Rahman IA, Padavettan V (2012) Synthesis of silica nanoparticles by sol-gel: size-dependent properties, surface modification, and applications in silica-polymer nanocomposites-a review. $\mathbf{J}$ Nanomater 1687-4110

98. Singh R, Bedi P, Fraternali F, Ahuja IPS (2016) Effect of single particle size, double particle size, and triple particle size $\mathrm{Al}_{2} \mathrm{O}_{3}$ in Nylon-6 matrix on mechanical properties of feed stock filament for FDM. Compos Part B 106:20-27

99. Khalil KA (2012) Advanced sintering of nano-ceramic materials. Ceramic materials - progress in modern ceramics 
100. Zazouli MA, Ebrahimzadeh MA, Charati JY, Dezfoli AS, Rostamali E, Veisi F (2013) Effect of sunlight and ultraviolet radiation in the titanium dioxide $\left(\mathrm{TiO}_{2}\right)$ nanoparticles for removal of furfural from water. J Mazand Univ Med Sci 23(107):126-138

101. Fiocco L, Michielsen B, Bernardo E (2016) Silica-bonded apatite scaffolds from calcite-filled preceramic polymers. J Eur Ceram Soc 36(13):3211-3218

102. Du X, Fu S, Zhu Y (2018) 3D printing of ceramic-based scaffolds for bone tissue engineering: an overview. J Mater Chem B 6(27):4397-4412

103. Uskokovi V, Uskokovi DP (2011) Nanosized hydroxyapatite and other calcium phosphates: chemistry of formation and application as drug and gene delivery agents. J Biomed Mater Res Part B 96:152-191

104. Sarath CV, Baskar G, Suganthi R (2012) Blood compatibility of iron-doped nanosize hydroxyapatite and its drug release. ACS Appl Mater Interfaces 4:1200-1210

105. Yu J, Chu X, Cai Y, Tong P, Yao J (2014) Preparation and characterization of antimicrobial nano-hydroxyapatite composites. Mater Sci Eng 37:54-59

106. Pinto R, Neves M, Neto CP, Trindade T (2012) Composites of cellulose and metal nanoparticles. Nanocomposites New Trends Dev

107. Masood SH, Song WQ (2004) Development of new metal / polymer materials for rapid tooling using Fused deposition modelling. Mater Des 25:587-594

108. Carlson C, Hussain SM, Schrand AM, Braydich-Stolle LK, Hess KL, Jones RL, Schlager JJ (2008) Unique cellular interaction of silver nanoparticles: size-dependent generation of reactive oxygen species. J Phys Chem B 112(43):13608-13619

109. Cady NC, Behnke JL, Stirckland AD (2011) Copper-based nanostructured coatings on natural cellulose: Nanocomposites exhibiting rapid and efficient inhibition of a multi-drug resistant would pathogen, A. baumannii, and mammalian cell biocompatibility in vitro. Adv Funct Mater 21(13):2506-2514

110. Smith AM, Nie S (2010) Semiconductor nanocrystals structure, properties, and band gap engineering. Acc Chem Res 43(2):190-200

111. Khairagarh IKSV (2019) Semiconductor nanoparticles theory and applications. Int J Appl Eng Res 14(2):491-494

112. Neudeck PH, Okojie RS, Chen L (2002) High-temperature electronics-A role for wide bandgap semiconductors? Proc IEEE 90(6):1065-1076

113. Lee S, Yan D, Zhou X, Cui H, Esworthy T, Han SY, Zhang LG (2020) Integrating cold atmospheric nanocomposite scaffold for cartilage regeneration. Mater Sci Eng C 111:110844

114. Gnanasekaran K, Heijmans T, van Bennekom S, Woldhuis H, Wijnia S, de With G, Friedrich H (2017) 3D printing of CNTand graphene-based conductive polymer nanocomposites by fused deposition modelling. Appl Mater Today 9:21-28

115. Lee H, Yoo JK, Park JH (2012) A stretchable polymer-carbon nanotube composite electrode for flexible lithium-ion batteries: Porosity engineering by controlled phase separation. Adv Energy Mater 2(8):976-982

116. Chen J, Liu Y, Minett AI (2007) Flexible, aligned carbon nanotube/conducting polymer electrodes for a lithium-ion battery. Chem Mater 19(15):3595-3597

117. Sahithi K, Swetha M, Ramasamy K (2010) Polymeric composites containing carbon nanotubes for bone tissue engineering. Int $\mathrm{J}$ Nanomed 6:2483

118. Deshmukh K, Ahamad MB, Deshmukh RR, Pasha SKK, Sadasivuni KK, Polu AR, Chidambaram K (2016) Newly developed biodegradable polymer nanocomposites of cellulose acetate and $\mathrm{A} 12 \mathrm{O} 3$ nanoparticles with enhanced dielectric performance for embedded passive applications. J Mater Sci Mater Electron 28(1):973-986
119. Javadi A, Pan S, Li X (2018) Manufacturing of Al and Mg nanocomposite microparticles. Manuf Lett 17:23-26

120. Chen S, Hassanzadeh-Aghdam MK, Ansari R (2018) An analytical model for elastic modulus calculation of $\mathrm{SiC}$ whiskerreinforced hybrid metal metrix nanocomposite containing $\mathrm{SiC}$ nanoparticles. J Alloy Compd 767:632-641

121. Park JJ, Lee JY, Hong YG (2020) Effects of vinylsilane-modified nanosilica particles on electrical and mechanical properties of silicone rubber nanocomposites. Polymer 197:122493

122. Ray J, Jana S, Mondal B, Tripathy T (2018) Enhanced and rapid adsorptive removal of toxic organic dyes from aqueous solution using a nanocomposite of saponified polymethyl acrylate grafted dextrin with embedded nanosilica. J Mol Liq 275:879-894

123. Nolan H, Sun D, Falzon BG, Chakrabarti S, Padmanaba DB, Maguire P, Mariotti D, Yu T, Jones D, Andrews G, Sun D (2018) Metal nanoparticle-hydrogel nanocomposites for biomedical applications - an atmospheric pressure plasma synthesis approach. Plasma Process Polym 15(11):1800112

124. Maneerung T, Tokura S, Rujiravanit R (2008) Impregnation of silver nanoparticles into bacterial cellulose for antimicrobial wound dressing. Carbohydr Polym 72(1):43-51

125. Chen J, Han CM, Lin XW, Tang ZJ, Su SJ (2006) Effect of silver nanoparticle dressing on second degree burn wound. Zhonghua Wai Ke Za Zhi 44(1):50-52

126. Palomba M, Carotenuto G, Cristino L, di Grazia MA, Nicolais F, de Nicola S (2012) Activity of antimicrobial silver polystyrene nanocomposites. J Nanomater

127. Cioffi N, Torsi L, Ditarantano N, Tantalillo G, Ghibelli L, Sabbatini L, Bleve-Zacheo T, D'Alessio M, Zambonin PG, Traversa E (2005) Copper nanoparticle/polymer composites with antifungal and bacteriostatic properties. Chem Mater 17:5255-5262

128. Delgado K, Quijada R, Palma R, Palza H (2011) Polypropylene with embedded copper metal or copper oxide nanoparticles as a novel plastic antimicrobial agent. Lett Appl Microbiol 53:50-54

129. Naderi KE, Guo W, Wang X, Xing W, Song L, Hu Y (2019) Effect of metal-based nanoparticles decorated graphene hybrids on flammability of epoxy nanocomposites. Compos Part A Appl Sci Manuf 129:105694

130. Lewis K (2007) Persister cells, dormancy and infectious disease. Nat Rev Microbiol 5:48-56

131. Gu Y, Chen X, Lee JH, Monteiro DA, Wang H, Lee WY (2012) Inkjet printed antibiotic- and calcium-eluting bioresorbable nanocomposite micropatterns for orthopedic implants. Acta Biomater 8(1):424-431

132. Aktitiz I, Varol R, Akkurt N, Sarac MF (2020) In-situ synthesis of 3D printable mono- and bi-metallic $(\mathrm{Cu} / \mathrm{Ag})$ nanoparticles embedded polymeric structures with enhanced electromechanical properties. Polym Test 90:106724

133. Lin D, Jin S, Zhang F, Wang C, Wang Y, Zhou C, Cheng GJ (2015) 3D stereolithography printing of graphene oxide reinforced complex architectures. Nanotechnology 26(43):434003

134. Manapat JZ, Mangadlao JD, Tiu BDB, Tritchler GC, Advincula RC (2017) High-strength stereolithographic 3D printed nanocomposites: Graphene oxide metastability. ACS Appl Mater Interfaces 9(11):10085-10093

135. Rafiee MA, Rafiee J, Wang Z, Song H, Yu ZZ, Koratkar N (2009) Enhanced mechanical properties of nanocomposites at low graphene content. ACS Nano 3(12):3884-3890

136. Gnanasekaran K, Heijamans T, Bennekom SV, Woldhuis H, Wijnia S, With G, Friedrich H (2017) 3D printing of CNT- and graphene-based conductive polymer nanocomposites by fused deposition modelling. Appl Mater Today 9:21-28

137. Zachary TA, Ghasemi NMN (2020) Additive manufacturing/3D printing of polymer nanocomposites: structure-related 
multifunctional properties. In: Structure and properties of additive manufactured polymer components, pp 87-113

138. Kim H, Shuvo MAI, Karim H, Nandasiri MI, Schwarz AM, Vijayakumar M (2017) Porous carbon/ $\mathrm{CeO}_{2}$ nanoparticles hybrid material for high-capacity super capacitors. MRS Adv 2(46):1-10

139. Dang ZM, Yuan JK, Zha JW, Zhou T, Li ST, Hu GH (2012) Fundamentals, processes and applications of high-permittivity polymermatrix composites. Prog Mater Sci 57:660-723

140. Kim H, Johnson J, Chavez LA, Garcia Rosales CA, Tseng TLB, Lin Y (2018) Enhanced dielectric properties of three phase dielectric $\mathrm{MWCNTs} / \mathrm{BaTiO}_{3} / \mathrm{PVDF}$ nanocomposites for energy storage using fused deposition modelling 3D printing. Ceram Int 44(8):9037-9044

141. Ko H, Yi H, Jeong HE (2017) Wall and ceiling climbing quadruped robot with superior water repellency manufactured using 3D printing (UNIclimb). Int J Precis Eng Manuf Green Technol 4(3):273-280

142. Sinha SK (2020) Additive manufacturing (AM) of medical devices and scaffolds for tissue engineering based on $3 \mathrm{D}$ and $4 \mathrm{D}$ printing. In: $3 \mathrm{D}$ and $4 \mathrm{D}$ printing of polymer nanocomposites materials, $\mathrm{pp}$ $119-160$

143. Pawar AA, Saada G, Cooperstein I, Larush L, Jackman J, Cho NJ, Magdassi S (2016) High-performance 3D printing of hydrogels by water-dispersible photoinitiator nanoparticles. Sci Adv 2(4):e1501381

144. Esmi A, Jahani Y, Yousefi A, Zandi M (2019) PMMA-CNT-HAp nanocomposites optimized for 3D-printing applications. Mater Res Express 6(8):085405

145. Wang W, Yeung WK (2017) Bone grafts and biomaterials substitutes for bone defect repair: a review. Bioactive Mater 2(4):224-247

146. Roopayath UK, Soni R, Mahanta U, Deshpande AS, Rath SN (2019) $3 \mathrm{D}$ printable $\mathrm{SiO}_{2}$ nanoparticles ink for patient specific bone regeneration, vol 41. Department of Material Science and Metallurgical Engineering

147. Brammer KS, Frandsen CJ, Jin S (2012) $\mathrm{TiO}_{2}$ nanotubes for bone regeneration. Trends Biotechnol 30(6):315-322

148. Sitharaman B, Shi X, Walboomers XF et al (2008) In vivo biocompatibility of ultra-short single-walled carbon nanotube/biodegradable polymer nanocomposites for bone tissue engineering. Bone 43(2):362-370

149. Han X, Xu H, Che L, Sha D, Huang C, Meng T, Song D (2020) Application of inorganic nanocomposite hydrogels in bone tissue engineering. iScience 23(12): 101845

150. Shrestha $C$ (2018) A study of 3D printed silver-polymer composite structures. The Department of Mechanical Engineering of the University of New Orleans

151. Kanmani P, Rhim JW (2014) Physicochemical properties of gelatin/silver nanoparticle antimicrobial composite films. Food Chem 148:162-169

152. Azlin-Hasim S, Cruz-Romero MC, Morris MA, Cummins E, Kerry JP (2015) Effects of a combination of antimicrobial silver low density polyethylene nanocomposite films and modified atmosphere packaging on the shelf life of chicken breast fillets. Food Packag Shelf Life 4:26-35

153. Kuuliala L, Pippuri T, Hultman J, Auvinen SM, Kolppo K, Nieminen T, Karp M, Björkroth J, Kuusipalo J, Jääskeläinen E (2015) Preparation and antimicrobial characterization of silver-containing packaging materials for meat. Food Packag Shelf Life 6:53-60

154. Li L, Chanjuan Z, Yadong Z, Jianfeng Y, Wenjian Y, Qiuhui H, Cailin W, Chongjiang W (2017) Effect of stable antimicrobial nano-silver packaging on inhibiting mildew and in storage of rice. Food Chem 215:477-482

155. Matilainen A, Vepsalainen M, Sillanpaa M (2010) Natural organic matter removal by coagulation during drinking water treatment: a review. Adv Colloid Interface Sci 159:189-197

156. Odling G, Robertson N (2018) Why is anatase a better photocatalyst than rutile? The importance of free hydroxyl radicals. Chemsuschem 8(11):1838-1840
157. Morones-Ramirez JR, Winkler JA, Spina CS, Collins JJ (2013) Silver enhances antibiotic activity against gram-negative bacteria. Sci. Transl. Med 5:190ra81

158. Verma UP, Mishra AK, Sinha MN (2020) Do piezoelectric and piezomagnetic sensors like, $\mathrm{BaTiO}_{2}, \mathrm{CoMnF}_{2}, \mathrm{CoF}_{2}$ felicitate propagation of electromagnetic signals induced dweue to stress within subsurface of crust and hence display pre-seismic signature? Mater Today Proc 39(1695): 1700

159. Gu H, Li G, Li P, Liu H, Trevor Chadyagondo T, Li N, Xiong J (2019) Superhydrophobic and breathable $\mathrm{SiO}_{2}$ /polyurethane porous membrane for durable water repellent application and oil-water separation. Appl Surf Sci 512:144837

160. Tao J, Xu X, Liu H, Jiang X, Mao J, Gou M (2020) A nanoparticlefunctionalized wound dressing device for toxin neutralization. Mater Des 188:108431

161. Carretta M, Boer BD, Jaques J, Antonelli A, Horton SJ, Yuan H, Brujin JD, Groen RWJ, Vellenga E, Schuringa JJ (2017) Genetically engineered mesenchymal stromal cells produce IL3 and TPO to further improve human scaffold-based xenograft models. Exp Hematol 51:36-46

162. Pahlevanzadeh F, Bakhsheshi-Rad HR, Kharaziha M, Kasiri-Asgarani M, Omidi M, Rzzaghi M, Ismail AF, Shariff S, Krishna SR, Berto F (2021) CNT and rGO reinforced PMMA basedbone cement for fixation of load bearing implants: Mechanical property and biological response. J Mech Behav Biomed Mater 116:104320

163. Shuai C, Yang W, Feng P, Peng S, Pan H (2021) Accelerated degradation of HAP/PLLA bone scaffold by PGA blending facilitates bioactivity and osteoconductivity. Bioactive Mater 6(2):490-502

164. Fielding G, Bose $\mathrm{S}$ (2013) $\mathrm{SiO}_{2}$ and $\mathrm{ZnO}$ dopants in three-dimensionally printed tricalcium phosphate bone tissue engineering scaffolds enhance osteogenesis and angiogenesis in vivo. Acta Biomater 9(11):9137-9148

165. Zhao X, Kuipers OP (2021) Synthesis of silver-nisin nanoparticles with low cytotoxicity as antimicrobials against biofilm-forming pathogens. Colloids Surf B Biointerfaces 206:111965

166. Vidales MJM, Marquez AN, Morcuende D, Atanes E, Blaya F, Soriano E, Martinez FF (2019) 3D printed floating photocatalysts for wastewater treatment. Catal Today 328:157-163

167. Yang X, Sun H, Li G, An T, Choi W (2021) Fouling of $\mathrm{TiO}_{2}$ induced by natural organic matters during photocatalytic water treatment: Mechanisms and regeneration strategy. Appl Catal B Environ 294:120252

168. Agarwala S, Goh GL, Goh GD, Dikshit V, Yeong WY (2020) 3D and 4D printing of polymer/CNTs-based conductive composites. In: 3D 4D Print Polym Nanocomposite Mater, pp 297-324

169. Hart LR, He Y, Ruiz-Cantu L, Zhou Z, Irvine D, Wildman R, Hayes W (2020) 3D and 4D printing of biomaterials and biocomposites, bioinspired composites, and related transformers. In: 3D and 4D printing of polymer nanocomposites materials, pp 467-504

170. Qi F, Chen N, Wang Q (2017) Preparation of PA11/BaTiO 3 nanocomposite powders with improved processability, dielectric and piezoelectric properties for use in selective laser sintering. Mater Des 131:135-143

171. Iwamoto S, Yamamoto S, Lee SH, Endo T (2014) Solid-state shear pulverization as effective treatment for dispersing lignocellulose nanofibers in polypropylene composites. Cellulose 21(3): 1573-1580

172. Wakabayashi K, Pierre C, Dikin DA, Ruoff RS, Ramanathan T, Brinson LC, Torkelson JM (2008) Polymer-graphite nanocomposites: effective dispersion and major property enhancement via solid-state shear pulverization. Macromolecules 41(6):1905-1908

Publisher's Note Springer Nature remains neutral with regard to jurisdictional claims in published maps and institutional affiliations. 